\title{
MORFOLOGÍA DE LAS ESPECIES DE ABELIA SECCIÓN VESALEA (CAPRIFOLIACEAE)
}

\author{
José Á. Villarreal-Quintanilla ${ }^{1,4}$, A. Eduardo Estrada-Castillón ${ }^{2}$, José L.

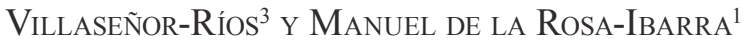 \\ ${ }^{1}$ Universidad Autónoma Agraria Antonio Narro, Departamento de Botánica, \\ Calzada Antonio Narro 1923, Buenavista, 25315 Saltillo, Coahuila, México. \\ ${ }^{2}$ Universidad Autónoma de Nuevo León, Facultad de Ciencias Forestales, Apdo. \\ postal 41, 67700 Linares, Nuevo León, México. \\ ${ }^{3}$ Universidad Nacional Autónoma de México, Instituto de Biología, Departamento \\ de Botánica, Apdo. postal 70-233, Ciudad Universitaria, \\ 04510 Coyoacán, México, D.F., México. \\ ${ }^{4}$ Autor para la correspondencia: javillarreal00@hotmail.com
}

\section{RESUMEN}

Abelia es un género de la familia Caprifoliaceae con distribución en Asia y América. Las cinco especies americanas conocidas se restringen a México y son las que conforman la sección Vesalea. Se hace una comparación de los rasgos morfológicos y anatómicos entre las especies mexicanas, con referencia a Abelia $\times$ grandiflora, y en ocasiones a otros elementos asiáticos. Los representantes de la sección Vesalea se caracterizan por tener glándulas nectaríferas en forma de banda y semillas obovadas.

Palabras clave: Abelia, Caprifoliaceae, Linnaeeae, morfología, Vesalea.

\begin{abstract}
Abelia is a genus of the family Caprifoliaceae distributed in Asia and America. The five known American species are restricted to Mexico and integrate the section Vesalea. The morphology and anatomy between the Mexican species is compared, with reference to Abelia $\times$ grandiflora and to some other Asiatic ones. The representatives of section Vesalea are characterized by having strap-like nectariferous glands and obovate seeds.
\end{abstract}

Key words: Abelia, Caprifoliaceae, Linnaeeae, morphology, Vesalea. 


\section{INTRODUCCIÓN}

El género Abelia ha sido tradicionalmente considerado como un elemento de la familia Caprifoliaceae. Backlund y Pyck (1998) lo clasificaron en la familia Linnaeaceae, que actualmente se reconoce como la tribu Linnaeeae (Landrein et al., 2012) dentro de Caprifoliaceae (s. 1.) (APG III, 2009) o alternativamente a nivel de subfamilia (Linnaeoideae; Stevens, 2001 onwards). Se distribuye en las áreas montañosas de las regiones templadas y tropicales del hemisferio norte (Good, 1974). Comprende unas 25 especies de arbustos con flores infundibuliformes o tubulares, cáliz persistente y fruto seco. La mayoría de las especies se localizan en Asia, mientras que en América el género está restringido a México (VillarrealQuintanilla et al., 2013). Abelia (sensu lato) está formada por las secciones Abelia y Zabelia que comprenden las especies asiáticas, y Vesalea que incluye a las mexicanas (Fukuoka, 1968). Las que conforman esta última, en un sentido general, son cinco con dos variedades adicionales: Abelia coriacea Hemsl. var. coriacea, conocida de una localidad en el sur de San Luis Potosí; A. coriacea var. subcoriacea Villarreal, distribuida en el norte del país en los estados de Chihuahua, Coahuila y Nuevo León; A. floribunda (M. Martens \& Galeotti) Decne. var. floribunda, de Puebla, Veracruz y norte de Oaxaca; A. floribunda var. foliacea Villarreal, del sur de Chiapas; A. grandifolia Villarreal, del norte de Querétaro; A. mexicana Villarreal, del oeste de Oaxaca y A. occidentalis Villarreal, del sur de Durango y norte de Jalisco (Villarreal-Quintanilla et al., 2013). Las asiáticas se caracterizan por la presencia de una glándula nectarífera en forma de almohadilla localizada en una protuberancia en la base del tubo de la corola, la cual está ausente en las americanas. Las glándulas nectaríferas en los representantes de la sección Vesalea se ubican en 1 o 3 bandas en la porción adaxial de la corola y el tubo de la corola carece de giba.

La morfología en Abelia ha sido poco estudiada, en especial la de las especies mexicanas de las cuales más de la mitad han sido descubiertas recientemente. Trabajos como los de Arreguín (1980) para polen, Sax y Kribs (1930) para cromosomas, Wilkinson (1948) de anatomía floral y Landrein y Prenner (2013) para el desarrollo de la inflorescencia en Caprifoliaceae son de los pocos reportados. Sobre morfología de elementos mexicanos de Abelia se encuentran los de Villarreal Quintanilla (2000, 2002, 2008). El propósito de este trabajo es presentar una descripción detallada y comparada de la morfología y anatomía de los elementos de la sección Vesalea con la finalidad de tener mayor entendimiento del grupo y poder definir mejor su taxonomía. 


\section{MÉTODOS}

En este estudio se compara la morfología de las especies mexicanas (sección Vesalea). Se describen las partes aéreas de la planta como tallo, hojas, flores, fruto, semillas y polen, así como la anatomía foliar y floral de cada especie. En algunos casos se contrastó la información con la obtenida de Abelia $\times$ grandiflora (Rovelli ex André) Rehder, frecuentemente cultivada como planta de ornato y la de otras especies asiáticas. Para la toma de dimensiones de estructuras de la planta, se midieron 10 de ellas en tres ejemplares de cada especie (Cuadro 1) para así obtener el promedio y valores mínimos y máximos.

En el trabajo anatómico se emplearon tanto muestras frescas recolectadas en campo como las obtenidas de ejemplares de herbario. Estas últimas se hidrataron previamente y, al igual que las primeras, se fijaron en FAA. Después se deshidrata-

Cuadro 1. Ejemplares empleados para el análisis morfológico (con asterisco los que también se utilizaron para anatomía de la hoja), se anota su ubicación geográfica.

\begin{tabular}{|c|c|c|}
\hline Especie & Colector y herbario & Localidad \\
\hline Abelia $\times$ grandiflora & J. Á. Villarreal 8661 (ANSM)* & Distrito Federal \\
\hline \multirow[t]{4}{*}{ Abelia coriacea } & J. Rzedowski 4434 (MEXU)* & San Luis Potosí \\
\hline & E. Estrada et al. 2125 (ANSM)* & Nuevo León \\
\hline & F. Chiang 9269 (TEX) & Coahuila \\
\hline & T. F. Patterson 6782 (TEX) & Nuevo León \\
\hline \multirow[t]{3}{*}{ Abelia floribunda } & J. A. Villarreal et al. 8225 (ANSM)* & Oaxaca \\
\hline & J. Á. Villarreal 8602 (ANSM) & Oaxaca \\
\hline & J. Á. Villarreal 8223 (ANSM) & Puebla \\
\hline \multirow[t]{3}{*}{ Abelia grandifolia } & B. Servín 1101 (IEB)* & Querétaro \\
\hline & E. Carranza 2876 (IEB) & Querétaro \\
\hline & B. Servín 1299 (IEB) & Querétaro \\
\hline \multirow[t]{3}{*}{ Abelia mexicana } & I. Calzada et al. 21100 (ANSM)* & Oaxaca \\
\hline & D. E. Breedlove 69627 (CAS) & Oaxaca \\
\hline & J. Á. Villarreal 8601 (ANSM) & Oaxaca \\
\hline \multirow[t]{3}{*}{ Abelia occidentalis } & J. Á. Villarreal et al 8180 (ANSM)* & Durango \\
\hline & A. García 2406 (ANSM) & Durango \\
\hline & S. González 3804 (ANSM) & Durango \\
\hline
\end{tabular}


ron en forma gradual con etanol a 30\%, 50\%, 70\%, 96\% y absoluto, y se aclararon en una solución de etanol absoluto-xilol (1:1) y xilol. Posteriormente se pasaron a una mezcla de xilol y parafina (1:1) y luego a parafina pura a $60{ }^{\circ} \mathrm{C}$ por 24 horas cada una. Las muestras se incluyeron en bloques de tamaño apropiado para cortar al microtomo. Los cortes se adhirieron al portaobjetos con una capa de grenetina disuelta y posteriormente se hicieron pruebas de tinción con la técnica de safraninaverde rápido y se montaron con bálsamo de Canadá. En cada estructura anatómica se realizaron observaciones en al menos tres laminillas por especie.

Para evidenciar los patrones de venación en las hojas y los lóbulos del cáliz, las muestras tomadas se transparentaron, usando las técnicas convencionales. Las partes por estudiar se colocaron en una solución de $\mathrm{NaOH}$ a 5\% durante 3-10 días a $37{ }^{\circ} \mathrm{C}$. Se deshidrataron gradualmente en etanol a $30 \%$ y $50 \%$, luego se tiñeron en una solución de safranina a $1 \%$ en alcohol a $50 \%$ y se continuó con etanol a $70 \%, 96 \%$ y absoluto. Para aclarar se empleó una mezcla de alcohol y xilol (1:1) y posteriormente xilol. En el montaje se empleó bálsamo de Canadá. Las fotomicrografías al microscopio electrónico de barrido fueron tomadas en un S-2 460N Hitachi en el Instituto de Biología de la Universidad Nacional Autónoma de México. El material utilizado que sirvió de referencia para el trabajo anatómico se enlista en el Cuadro 1.

\section{RESULTADOS}

La morfología comparativa es una herramienta que ayuda a entender las características de un grupo. Cuando el estudio se restringe a un conjunto pequeño de taxa muy relacionados, como en este caso, es muy probable que los cambios evolutivos no se perciban, por lo que es recomendable que se incluyan otras plantas de grupos cercanos.

Forma de crecimiento: Los elementos de Abelia en México son arbustos ramificados, con tallos postrados en $A$. grandifolia y erectos en el resto de las especies. El tamaño varía de unos $30 \mathrm{~cm}$ en especímenes de $A$. coriacea var. subcoriacea en el noroeste de Coahuila y noreste de Chihuahua, a un poco más de $2 \mathrm{~m}$ de alto en algunos ejemplares de $A$. floribunda en Oaxaca. Las ramas son opuestas, alargadas y flexibles en las plantas de hábitats mésicos, mientras que en las de las regiones más áridas llegan a ser rígidas y espinescentes. Al parecer, la variación entre especies e intraespecífica se debe a diferencias en las condiciones ambientales entre los lugares donde se desarrollan. 
Crecen usualmente en laderas pedregosas de poca pendiente, comúnmente en bosques de pino-encino y matorral submontano. La mayoría lo hace en suelos calizos, excepto $A$. coriacea var. coriacea, que se desarrolla en los derivados de rocas de origen ígneo.

Tallo: El tallo en sección transversal es circular a ligeramente anguloso, con diámetro en la porción media de la planta que va de 4 a $8 \mathrm{~mm}$. Es común que la epidermis junto con la corteza secundaria se desprenda en tiras alargadas en la madurez. Las ramas generalmente tienen ligeros engrosamientos en los nudos y la distancia internodal va de 3-12 mm en la mayor parte de las especies, y hasta $45 \mathrm{~mm}$ de largo en ejemplares de $A$. mexicana y A. floribunda; este carácter usualmente está relacionado con la frondosidad de la planta. En contraste, en los representantes de la sección Zabelia es característico que se presenten ramas con ranuras longitudinales y nudos muy engrosados.

Vascularización nodal: La vascularización nodal es de tres trazas, con las laterales separándose del cilindro vascular medio abajo de la traza vascular foliar media. La base del pecíolo muestra tres trazas libres, que se unen un poco más adelante en una sola que continúa hasta la nervadura media del limbo, lo cual corresponde con lo reportado por Metcalfe y Chalk (1950) para otros miembros de la familia. La hoja muestra una central media y dos laterales.

Hoja: Las hojas son opuestas y pecioladas. Las estípulas son diminutas, de 0.1-0.2 mm de largo, a frecuentemente ausentes. Las hojas maduras usualmente empiezan a caer en el otoño y son sustituidas en primavera por las nuevas. Los limbos son planos a ligeramente plegados en la nervadura media en todas las especies; solo las plantas de $A$. grandifolia y las de A. floribunda var. foliacea muestran superficies abolladas con nerviación muy evidente. Los dientecillos del margen usualmente presentan glándulas apicales. Las características de las hojas de las abelias mexicanas se comparan en el Cuadro 2.

Venación: La venación es pinnada, reticulódroma (Hickey, 1973), tanto en hojas enteras como en las que presentan margen serrulado. La vena media es recta a ligeramente sinuosa, ancha, ocupando de 3 a 4\% del ancho del limbo (Fig. 1). Las secundarias son divergentes de la vena media en ángulo recto a casi recto en la parte media y apical de la hoja; las inferiores se disponen en ángulo obtuso. Las secundarias son gruesas, curvadas en la parte distal, uniéndose a la vena secundaria suprayacente en ángulo obtuso y formando en la porción cercana al margen una venación intramarginal que se conecta al borde y a las glándulas marginales. Una línea marginal libre de venación de 0.1-0.2 mm de ancho se presenta en el borde de la hoja, la cual es más evidente en $A$. coriacea. Las venas terciarias se originan en ángulo recto o casi recto de 
Cuadro 2. Variación morfológica de la hoja en los taxa de Abelia sección Vesalea.

\begin{tabular}{|c|c|c|c|c|}
\hline Caracteres & \multicolumn{4}{|c|}{ Especies } \\
\hline & A. coriacea coriacea & \multirow{2}{*}{\multicolumn{2}{|c|}{$\begin{array}{c}\text { A. coriacea subcoriacea } \\
\text { ovada-circular }\end{array}$}} & \multirow{2}{*}{$\begin{array}{l}\text { A. floribunda floribunda } \\
\text { oblonga-ovada }\end{array}$} \\
\hline Forma & elíptica & & & \\
\hline Textura & coriácea & \multicolumn{2}{|c|}{ subcoriácea } & $\begin{array}{l}\text { oblonga-ovada } \\
\text { herbácea }\end{array}$ \\
\hline Grosor (mm) & $0.45-0.55$ & \multicolumn{2}{|c|}{$0.38-0.42$} & \\
\hline Base & redondeada & \multicolumn{2}{|c|}{ redondeada } & cuneada \\
\hline Ápice & agudo & \multicolumn{2}{|c|}{ obtuso-redondeado } & btuso-redondeado \\
\hline Margen & entero & \multicolumn{2}{|c|}{ entero } & serrulado \\
\hline Caracteres & \multicolumn{4}{|c|}{ Especies } \\
\hline & A. floribunda foliacea & A. grandifolia & A. mexicana & A. occidentalis \\
\hline Forma & oblonga-elíptica & elíptica-ovada & elíptica-rómbica & elíptica \\
\hline Textura & herbácea & subcoriácea & herbácea & herbácea \\
\hline Grosor (mm) & $0.25-0.35$ & $0.38-0.42$ & $0.25-0.35$ & $0.25-0.35$ \\
\hline Base & cuneada & redondeada & cuneada & cuneada \\
\hline Ápice & obtuso-redondeado & $\begin{array}{l}\text { obtuso- } \\
\text { redondeado }\end{array}$ & agudo & $\begin{array}{l}\text { obtuso- } \\
\text { redondeado }\end{array}$ \\
\hline Margen & serrulado & serrulado & serrulado & entero-serrulado \\
\hline
\end{tabular}

las secundarias, con un patrón de ramificación transverso dividido. Las cuaternarias son distinguibles, con un curso ortogonal que da origen a la venación quinternaria. Las areólas son imperfectas, usualmente pentagonales y de tamaño medio.

Los lóbulos del cáliz presentan venación semicraspedódroma, con la vena principal evidente y las secundarias conectadas y con una ramificación terminando en el margen. El patrón de venación en las hojas y los lóbulos del cáliz es constante para las especies mexicanas, encontrándose el mismo al hacer la comparación con A. $\times$ grandiflora (Fig. 1).

Anatomía foliar: En sección transversal la epidermis está formada por una sola capa de células con paredes gruesas, cúbicas y grandes en el haz; en el envés son casi esféricas y más pequeñas. La hipodermis está ausente. El mesófilo es bifacial, consistente en un parénquima en empalizada formado por una hilera de células alargadas en $A$. floribunda y A. mexicana y dos en A. coriacea, A. grandifolia y $A$. occidentalis que ocupan aproximadamente de un tercio a la mitad del espacio del mesófilo (Fig. 2). El parénquima esponjoso lo constituyen células más cortas, con arreglo irregular que deja espacios. Los haces vasculares muestran vainas de colén- 

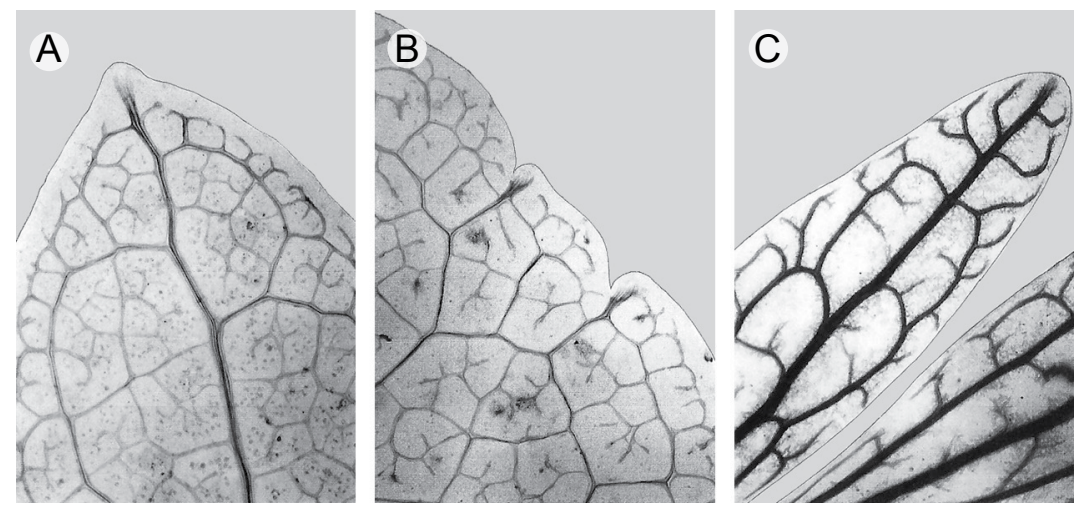

Fig. 1. Venación en la hoja de Abelia. A. hoja aclarada con la venación teñida. Nótese el patrón de venación; B. margen con dientes y el ensanchamiento de la vena terminal en la glándula; C. venación en los sépalos de A. floribunda.
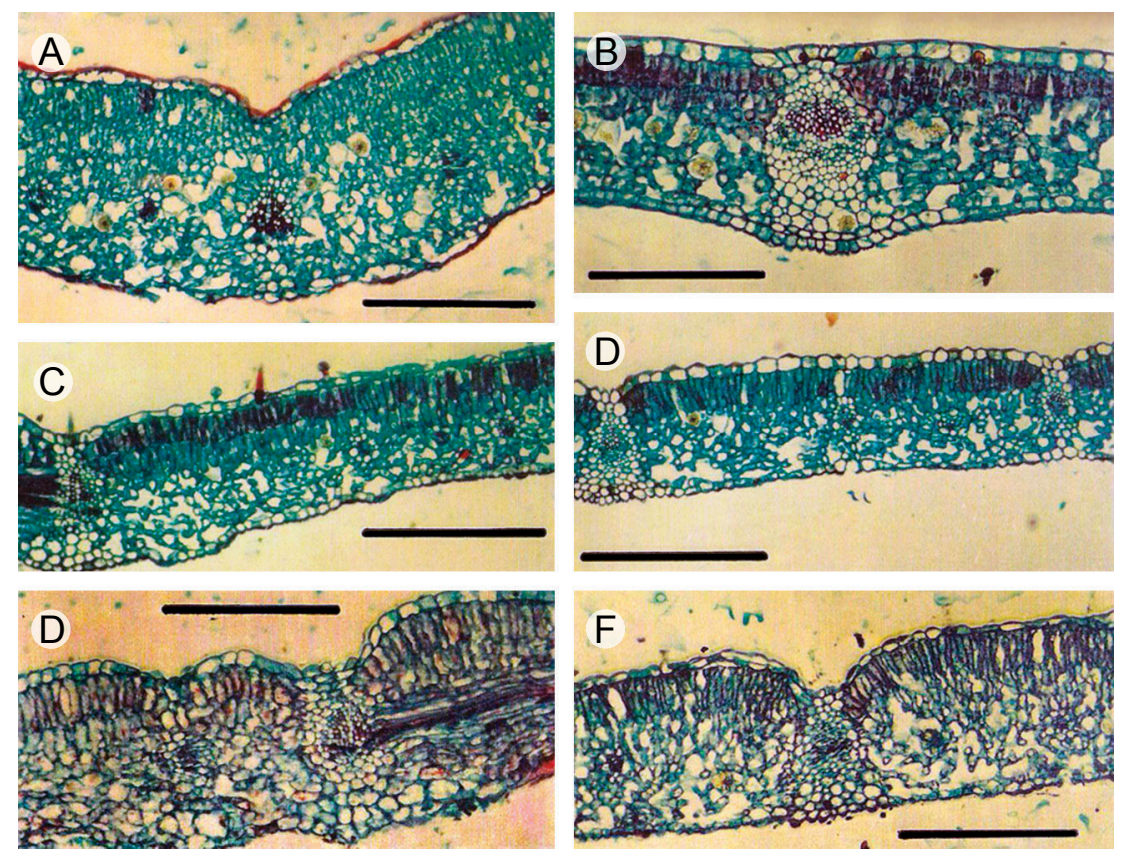

Fig. 2. Anatomía de la hoja de Abelia. Corte en sección transversal de la hoja de A. $A$. coriacea, B. A. x grandiflora, C. A. mexicana, D. A. floribunda, E. A. grandifolia y F. A. occidentalis. Se observa el parénquima en empalizada en una hilera en $\mathrm{C}$ y D, de dos a tres hileras en A, B y E, además de mesófilo, el haz vascular, la vaina del haz vascular y cistolitos. Barras horizontales de $0.5 \mathrm{~mm}$. 
quima de una célula de grosor, que se extienden hacia ambos lados hasta la epidermis en la vena principal y solo hacia el envés en las nervaduras secundarias en $A$. floribunda, $A$. occidentalis y $A$. mexicana. La vaina del haz vascular es de dos a tres células de grosor en $A$. coriacea y $A$. grandifolia, extendiéndose solo hacia el envés. En $A$. occidentalis existen haces de fibras subepidérmicas contiguos al colénquima en las nervaduras principales. También se presentan cristales tipo drusa esparcidos en los espacios del parénquima esponjoso. Abelia $\times$ grandiflora tiene hojas delgadas, de alrededor de $0.25 \mathrm{~mm}$ de grosor, dos hileras de células en el parénquima en empalizada, la vaina del haz vascular es de una célula de grosor y carece de extensiones hacia la epidermis, por lo cual muestra mayor similitud con A. occidentalis.

La epidermis está compuesta por células poligonales irregulares, las cercanas a las venas son alargadas con forma rectangular. La cutícula es delgada, de 1 a 2 $\mu \mathrm{m}$ de grueso. Sin embargo, es algo más engrosada en la parte media de las células donde forma papilas cortas, siendo más evidente en el haz que en el envés.

Los estomas son del tipo paracítico (Van Cotthem, 1970), con distribución anfiestomática y son más numerosos en el envés. Su orientación es irregular y están ausentes en los haces vasculares. Las células guardianes varían de 15 a $25 \mu \mathrm{m}$ de largo (Fig. 3).

Vestidura: La vestidura o indumento es evidente en los tallos jóvenes, envés de la hoja, corola y fruto. Ésta cambia en las diferentes especies de Abelia, es hispídula en $A$. coriacea y $A$. floribunda, con tricomas entre 0.01-0.04 mm de largo. En $A$. mexicana y $A$. grandifolia es híspida, con tricomas entre $0.045-0.060 \mathrm{~mm}$ de largo, y en $A$. occidentalis es estrigosa, con tricomas antrorsos en los tallos y ramillas. La vestidura está formada de dos tipos de tricomas, que de acuerdo con la terminología de Roe (1971) corresponden a: 1) Simples, unicelulares, ligeramente cónicos, con tamaños que varían de 0.01 a $0.06 \mathrm{~mm}$ de largo; al microscopio electrónico de barrido (MEB) los tricomas simples muestran una superficie granular (Fig. 3); sobresalen los tricomas de A. occidentalis, los cuales son curvados antrorsamente, a diferencia del resto de las especies que son más bien erectos a ligeramente curvados. 2) Glandulares, multicelulares, de unos $0.03 \mathrm{~mm}$ largo, con una cabezuela de cuatro células; están presentes en las ramillas y son especialmente abundantes en las hojas y en la cara adaxial de la corola (Figs. 3 y 4).

Inflorescencia: Las flores se presentan en inflorescencias cimosas en las axilas terminales de las ramas, usualmente en pares, en ocasiones solitarias (como es frecuente en A. floribunda) o raramente en grupos de tres. Los pedúnculos son de 1.0-2.5 $\mathrm{mm}$ de largo, con un par de brácteas en la base. Las flores son erectas en A. coriacea y péndulas en las otras especies, pueden ser sésiles o en pedicelos de hasta $2 \mathrm{~mm}$ de largo. 

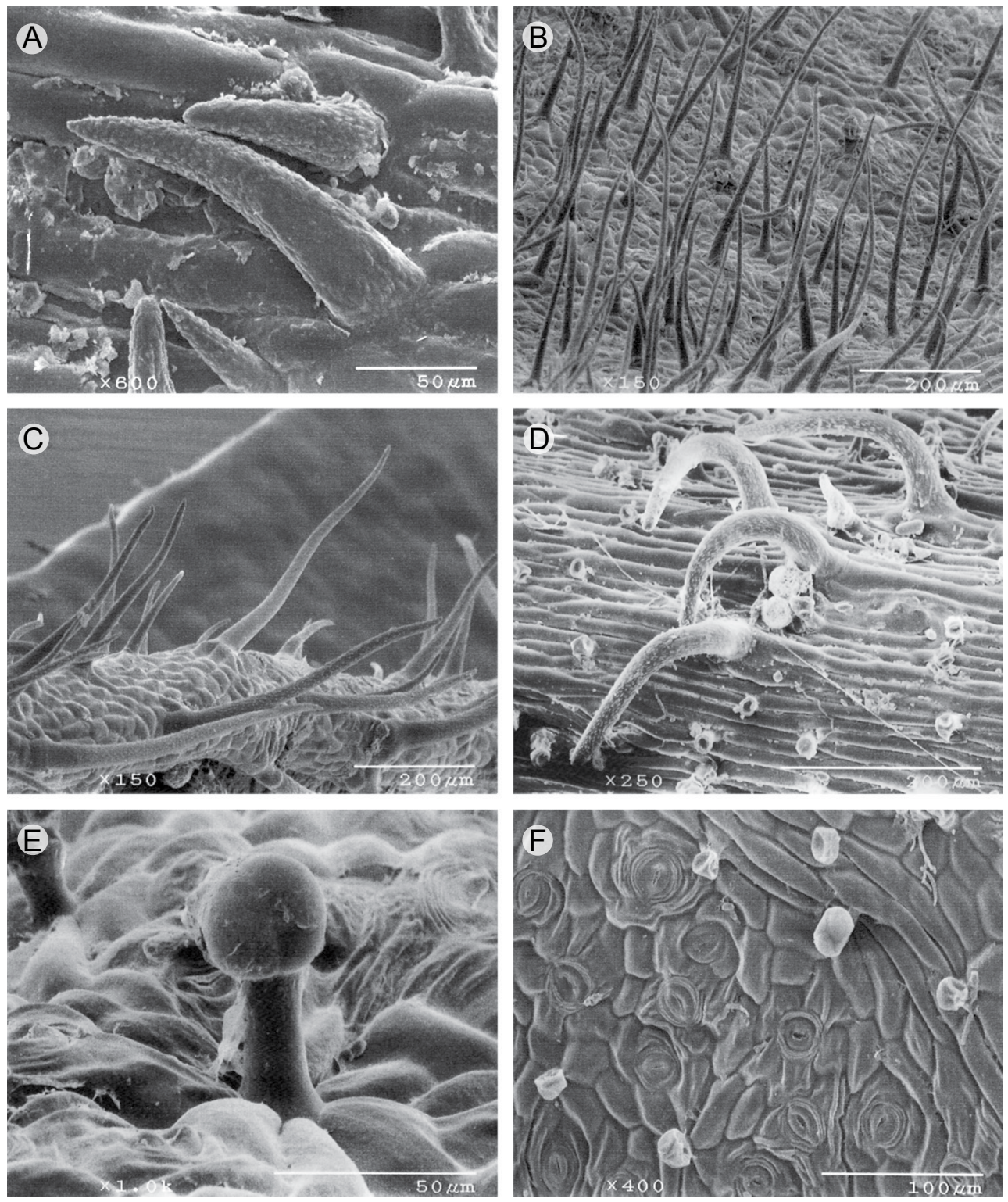

Fig. 3. Tricomas y estomas en Abelia vistos al microscopio electrónico de barrido. A. simples en $A$. coriacea; B. simples en A. mexicana; C. simples en $A$. grandifolia; D. simples en $A$. occidentalis; E. glandular en hoja de $A$. occidentalis y F. estomas en envés de hoja de $A$. occidentalis. 


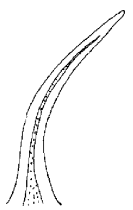

A

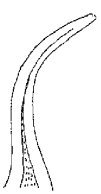

B

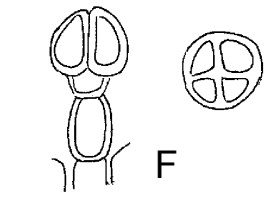

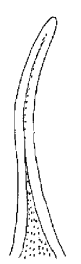

C

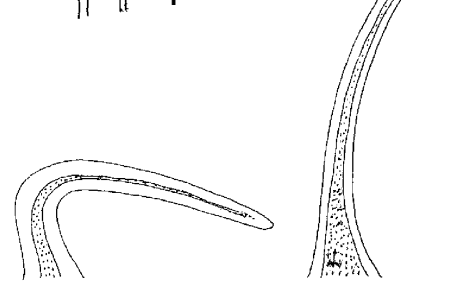

$E$

Fig. 4. Tricomas en Abelia. Unicelulares simples en A. A. coriacea; B. A. × grandiflora; C. A. floribunda; D. A. occidentalis y E. A. mexicana. Nótese el tamaño en A. mexicana y la forma en $A$. occidentalis. F. glandular multicelular en vista lateral y cabezuela de 4 células en vista superior en A. floribunda.

Cáliz: El cáliz es de cinco sépalos alargados, soldados en un tubo corto basal que corona el ovario ínfero. La forma de los sépalos es linear-lanceolada en $A$. coriacea, A. grandifolia, A. mexicana y $A$. occidentalis, mientras que es elíptica en A. floribunda, donde usualmente se presentan dos o más sépalos fusionados. Esta condición es frecuente en algunas especies asiáticas, como $A$. $\times$ grandiflora. En el botón los sépalos son valvados y el indumento es esparcido y semejante al del tallo. La vascularización es semicraspedódroma. El cáliz es ligeramente acrescente y persiste en el fruto.

El calículo está formado por cuatro bractéolas y se localiza en la base de la flor. En todas las especies las bractéolas son lineares a subuladas, de 0.3-2.5 mm de largo, excepto en A. floribunda var. foliosa, donde son obovadas de 3-7 $\mathrm{mm}$ de largo (Fig. 10).

Corola: La corola es gamopétala, tubular en A. floribunda e infundibuliforme en el resto de las especies. El tubo de la corola se expande gradualmente en $A$. coriacea, A. grandifolia y A. mexicana, mientras que en A. occidentalis es estrecho en la porción inferior y se expande bruscamente en la parte media. El color de la corola varía de blanco-rosado en $A$. coriacea, lila en $A$. mexicana, rosa en $A$. occidentalis a rojo bermejo en $A$. floribunda (Fig. 5). Los lóbulos son cinco, oblongo-obovados, el inferior es escasamente más grande, dando una forma ligeramente bilateral de la corola. La prefloración es imbricada y el lóbulo inferior es el más externo. Del lado adaxial la vestidura está representada por tricomas simples y glandulares. La parte externa de la corola es 

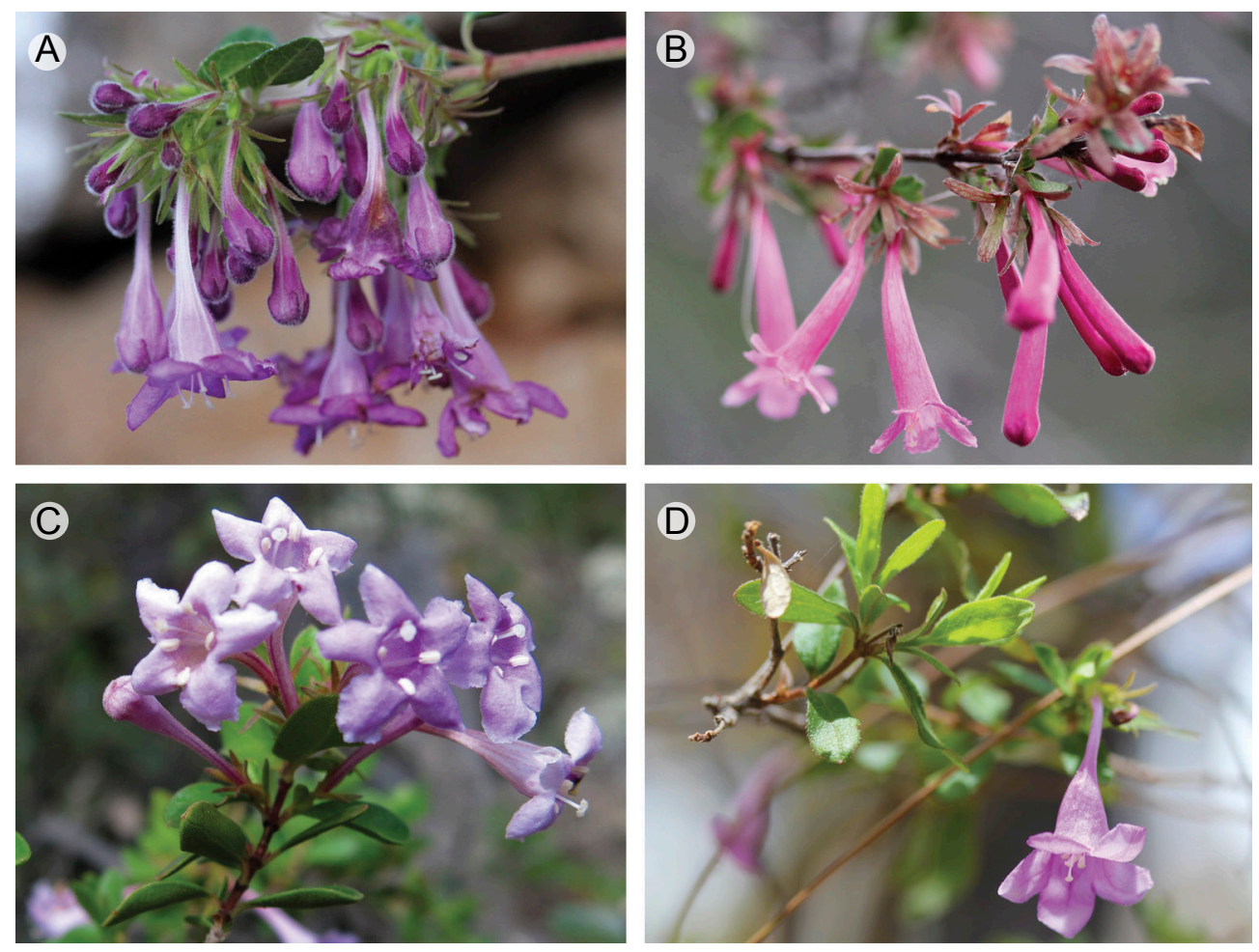

Fig. 5. Flores en Abelia. A. A. grandifolia; B. A. floribunda; C. A. coriacea y D. A. occidentalis.

pubescente, mientras que la interna es glabra, y solo con algunos tricomas simples en la porción inferior. Las características específicas se detallan en el Cuadro 3.

Androceo: El número de estambres es de cuatro, con un arreglo didínamo en todas las especies. Los inferiores son un poco más largos que los superiores y están dispuestos sobre la porción ventral de la corola. Los filamentos están soldados con el tercio inferior del tubo de la corola; son aplanados, blancos (algunas veces se vuelven negruzcos durante el secado), glabros en la parte superior y pilosos en la porción inferior. Las anteras son de dos tecas, glabras, amarillas, dorsifijas, con dehiscencia longitudinal introrsa, las paredes están formadas por dos a tres hileras de células de grueso, la más interna constituyendo el tapetum glandular.

Polen: Se analizaron los granos de polen de todas las especies mexicanas de Abelia. El polen es tectado, tricolpado o tetracolpado, circular en vista polar, de 50 a $80 \mu \mathrm{m}$ de diámetro y circular en vista ecuatorial, de 50 a $78 \mu \mathrm{m}$ de diámetro. Los colpos son de 22 a $44 \mu \mathrm{m}$ de largo. La exina es tectada, de 3.8 a $5.8 \mu \mathrm{m}$ de grueso (sin 
Cuadro 3. Características de la corola en las especies de Abelia sección Vesalea.

\begin{tabular}{lccccc}
\hline Caracteres & \multicolumn{5}{c}{ Especies } \\
\hline Color & $\begin{array}{c}\text { A. coriacea } \\
\text { blanco- } \\
\text { rosado }\end{array}$ & $\begin{array}{c}\text { A. floribunda } \\
\text { rojo bermejo }\end{array}$ & $\begin{array}{c}\text { A. grandifolia } \\
\text { rosa-lila }\end{array}$ & A. mexicana & A. occidentalis \\
Tamaño (mm) & $10-24$ & $22-40$ & $20-28$ & $21-29$ & rosa-lila \\
$\begin{array}{l}\text { Ancho base } \\
\text { del tubo (mm) }\end{array}$ & $1.8-2.3$ & $6.0-7.5$ & $1.8-2.3$ & $1.8-2.3$ & $1.8-2.3$ \\
$\begin{array}{l}\text { Ancho ápice } \\
\text { del tubo }(\mathrm{mm})\end{array}$ & $4-5$ & $7-8$ & $10-12$ & $8-10$ & $8-10$ \\
\hline
\end{tabular}

considerar las espinas), con una superficie equinada (supraequinada) y con espinas pequeñas de 0.5 a $3 \mu \mathrm{m}$ de largo, distribuidas regularmente sobre la superficie.

Las observaciones de la microestructura al MEB muestran que la superficie de los granos de polen tiene espinas y un tectum perforado irregularmente (Fig. 6). Abelia coriacea presenta una superficie con espinas cortas, de 0.5 a $0.8 \mu \mathrm{m}$ de largo y perforaciones de 3-8/4 $\mu \mathrm{m}^{2}$. Abelia floribunda tiene las espinas de mayores dimensiones, de 1.8 a $2.8 \mu \mathrm{m}$ de largo, escasas, con pocas perforaciones, de 0-3/4 $\mu \mathrm{m}^{2}$. Abelia grandifolia muestra espinas de 1.3 a $2.4 \mu \mathrm{m}$ de largo, escasas, con perforaciones en número de $0-4 / 4 \mu \mathrm{m}^{2}$. Abelia mexicana tiene espinas de 1.5 a $2.5 \mu \mathrm{m}$ de largo, escasas, y perforaciones de 10-20/4 $\mu \mathrm{m}^{2}$. En A. occidentalis las espinas son de 0.8 a $2.2 \mu \mathrm{m}$ de largo y las perforaciones de $12-20 / 4 \mu \mathrm{m}^{2}$. El corte de la exina en el polen de $A$. coriacea (solo se vio esta especie) muestra una estructura tectada, con una capa de nexina externa diferenciada de una sexina más interna; esta última presenta un sistema desarrollado de columelas que forman el tectum (Fig. 6K).

Gineceo: El ovario es ínfero, de tres carpelos y tres cavidades, de las que una comprende la mitad del ovario, es semicircular en sección transversal y alberga al óvulo fértil en la mayoría de las especies. Las otras dos ocupan el espacio restante, contienen 4-6 óvulos usualmente rudimentarios; en ocasiones se desarrolla uno de ellos como se muestra en la Fig. 7B. La placentación es axilar. El ovario se prolonga en un rostro estéril, el cual es casi tan largo como el ovario en $A$. occidentalis; de la mitad a un tercio del tamaño del fruto en $A$. floribunda, A. grandifolia y A. mexicana y menos de un tercio en $A$. coriacea (Fig. 10). El gineceo se continúa después del cáliz en un estilo alargado que termina en un estigma ligeramente trilobulado, subcapitado. Durante la antesis el estilo se alarga y el estigma queda exerto. 

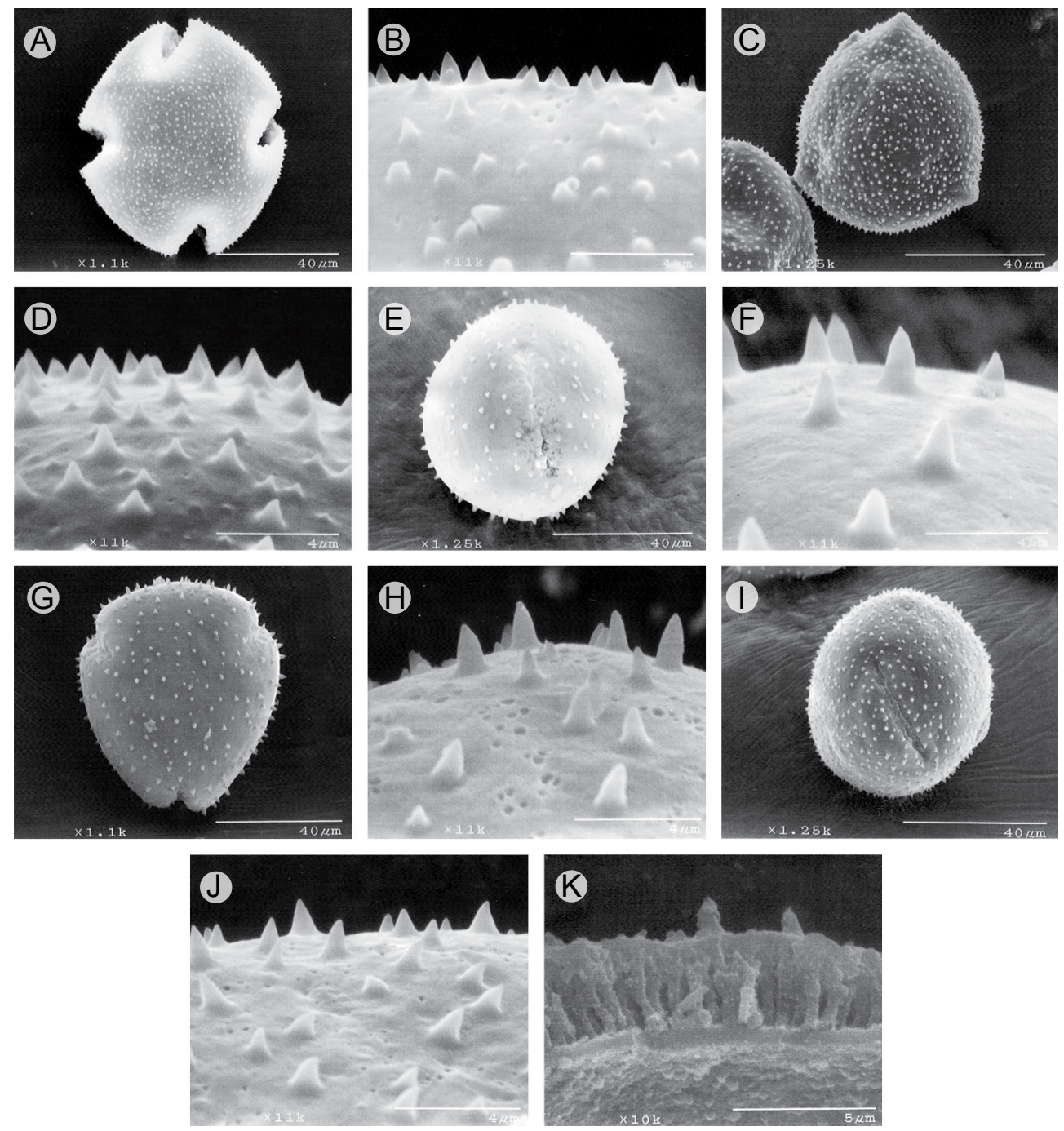

Fig. 6. Polen de Abelia visto al microscopio electrónico de barrido. A y B. vista polar y superficie en $A$. coriacea; C y D. en A. grandifolia; E y F. en A. floribunda; G y H. vista polar y superficie en $A$. mexicana; I y J. en $A$. occidentalis y K. corte de la exina en grano de polen de $A$. coriacea.

La vascularización de la flor se muestra en las figuras 13-17. Los haces en el ovario se distribuyen irregularmente, seis en la mitad estéril y tres un poco más engrosados en la fértil. En la porción inferior del rostro se diferencian unos 15 haces 
periféricos que vascularizan el cáliz y nueve más centrales que son los de la corola y androceo (Fig. 7C). La distribución y número de haces vasculares en la flor es constante en todas las especies mexicanas.

Glándula nectarífera: Existe una glándula nectarífera floral localizada en el lado ventral en el interior del tubo de la corola. Tiene apariencia de almohadilla en las especies asiáticas y está constituida por un engrosamiento multicelular en el epitelio interno. En la base de la corola se forma una pequeña giba que alberga esta glándula (Figs. 8E-F y 9E-F). La giba presenta de cuatro a cinco haces vasculares contiguos a la glándula. Las especies americanas no tienen corola con una giba en la base y la glándula es en forma de una banda estrecha, la cual ocupa la porción inferior del tubo y está formada por dos a tres hileras de células modificadas del epitelio. Solo un haz vascular se localiza en la corola del lado de la glándula (Fig. 8D). Abelia floribunda presenta tres bandas glandulares que se extienden cerca de una cuarta parte de la corola, en contraste, A. coriacea, A. grandifolia, A. mexicana y $A$. occidentalis exhiben una sola que se extiende aproximadamente un tercio de la longitud del tubo de la corola (Fig. 8).
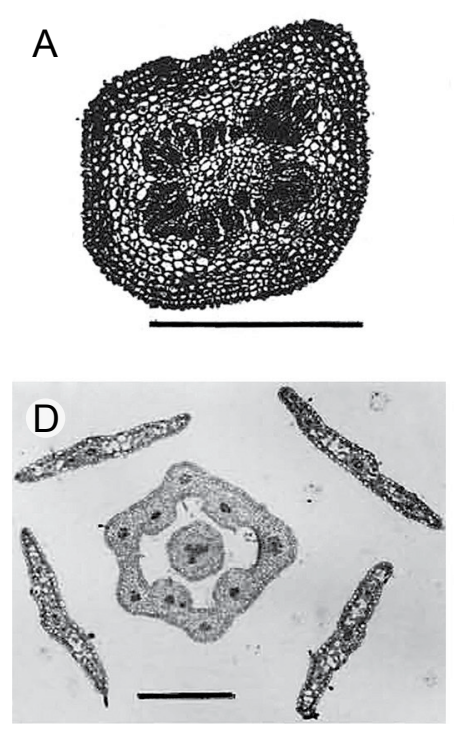
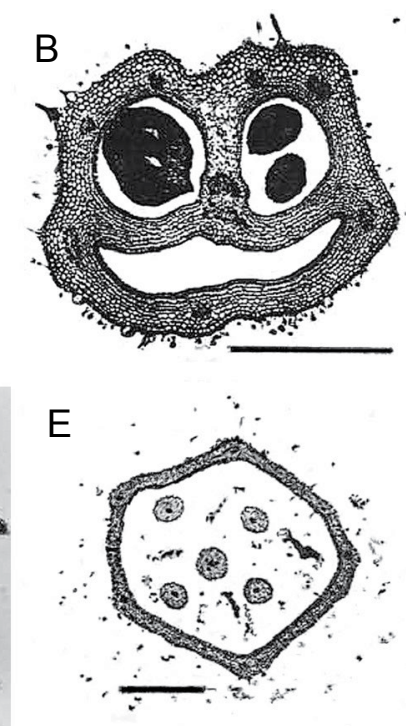
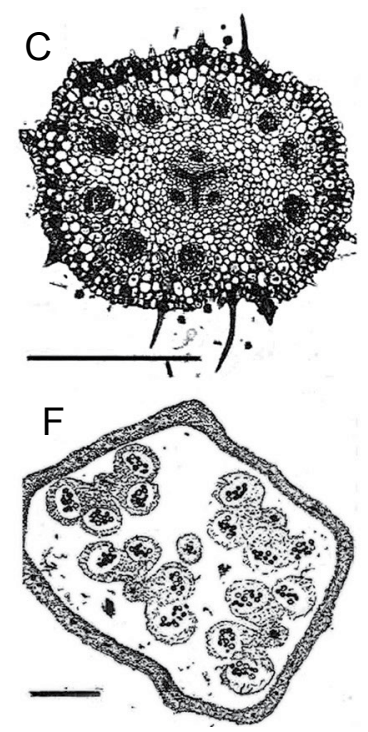

Fig. 7. Anatomía de la flor en Abelia floribunda. Cortes transversales de botón, A. base del ovario; B. ovario; C. rostro; D. base de la corola; E. corola, filamentos y estilo; F. corola y anteras. Barras de referencia de $0.5 \mathrm{~mm}$. 

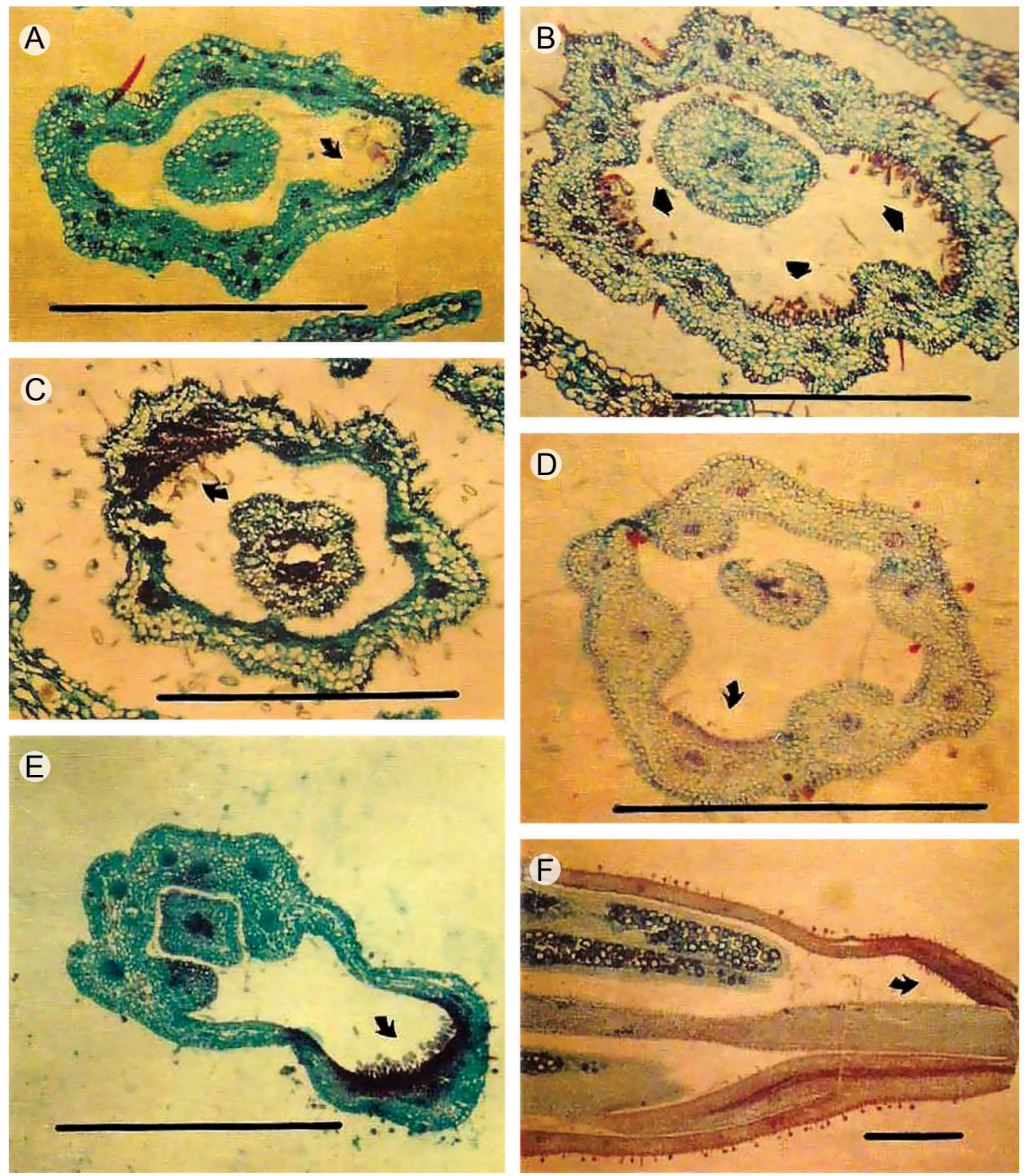

Fig. 8. Glándulas nectaríferas en Abelia vistas al microscopio óptico. Corte transversal de la base del tubo de la corola en botón. A. A. coriacea con una sola área glandular; B. $A$ floribunda con tres; C. A. mexicana con una sola; D. A. occidentalis con una sola; E y F. corte transversal y longitudinal de botón en $A$. $\times$ grandiflora, donde se muestra la giba y glándula nectarífera. Barras horizontales de $1 \mathrm{~mm}$. 

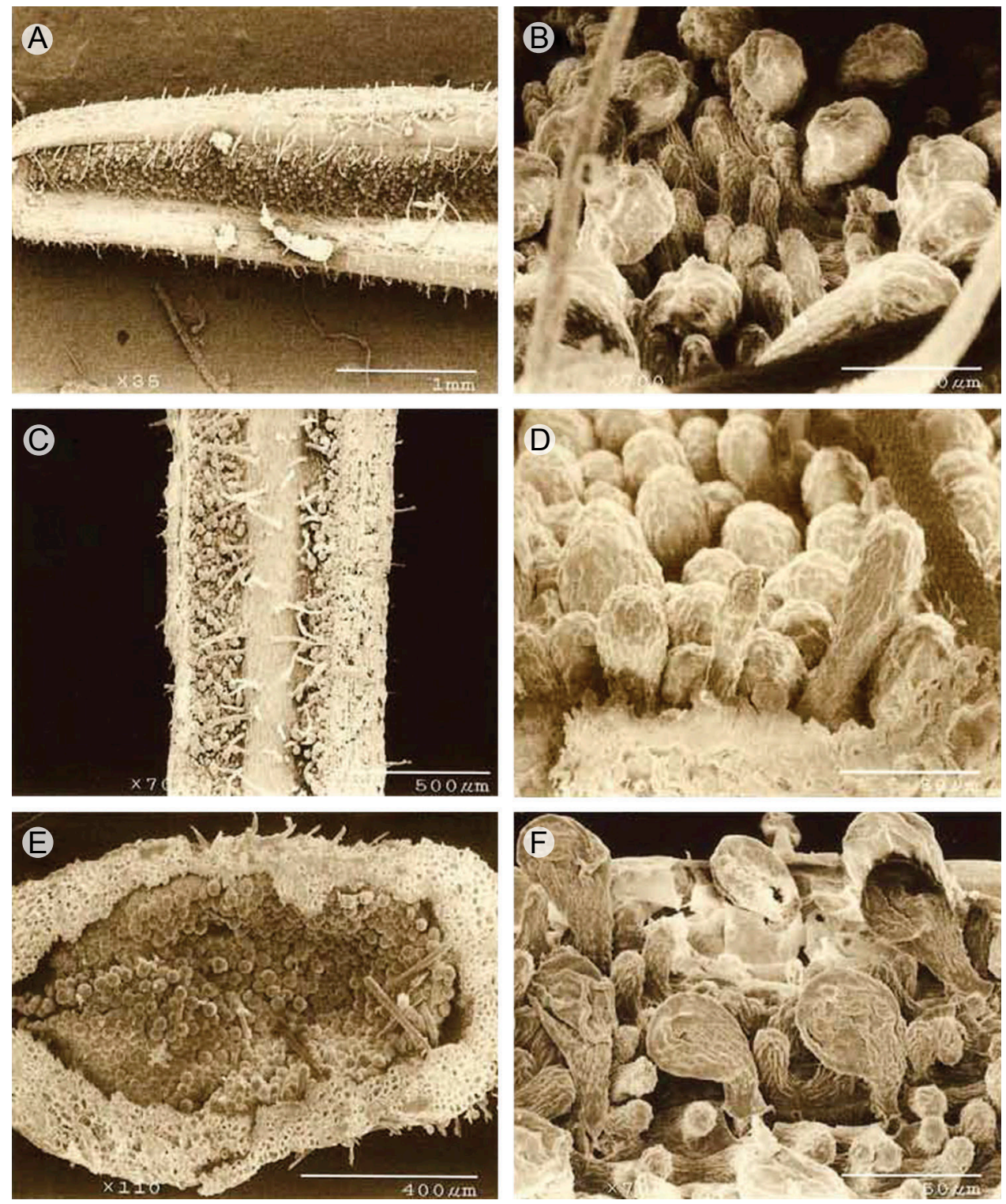

Fig. 9 . Glándulas nectaríferas en Abelia vistas al microscopio electrónico de barrido. Corte longitudinal en la base del tubo de la corola. A. glándula en una sola banda en A. occidentalis; B. vista de los tricomas glandulares de la glándula mostrada en A; C. dos glándulas en banda de las tres presentes en A. floribunda; D. vista de los tricomas glandulares mostrados en C; E. glándula en almohadilla en la giba en $A$. $\times$ grandiflora ; F. vista de los tricomas glandulares mostrados en E. 
La porción distal de la glándula muestra hileras de células con núcleos muy evidentes y citoplasma denso. Las de la hilera más externa se agrandan, tornándose claviformes, se rompen y liberan su contenido; posteriormente se desprenden y son sustituidas por las de la capa próxima inferior.

Se presentan nectarios extraflorales en los dientecillos del borde de las hojas; tienen forma cortamente cilíndrica, usualmente son oscuros y están formados por tejido secretor o epitema que forma una pequeña cavidad donde se acumula la secreción y un poro que comunica al exterior. Existe conexión del tejido con un pequeño haz vascular, en el que abunda el xilema.

Fruto: El ovario da origen a una cápsula indehiscente que está coronada por los lóbulos persistentes del cáliz. En las especies americanas está formado por un ensanchamiento basal ovado, mientras que en los representantes asiáticos el ovario es alargado y casi cilíndrico. La mitad del ovario está formada por dos lóculos estériles que contienen de 4 a 6 óvulos rudimentarios, aunque ocasionalmente desarrollan de 1 a 2 óvulos fértiles. La otra mitad la ocupa el lóculo fértil que desarrolla un solo óvulo. Externamente el ovario es asimétrico, con una cara plana del lado donde hay una cavidad y otra convexa del lado de las dos cavidades; también presenta costillas que corresponden a la nerviación. El fruto se continúa por encima de los lóculos en un cuello estrecho y estéril denominado rostro, el cual remata en el cáliz (Fig. 10). Es de suponer que por las dimensiones de los lóbulos del cáliz éstos ayudan en la dispersión anemófila del fruto. El fruto y el cáliz presentan vestiduras que van de hispídula con tricomas glandulares en $A$. coriacea y $A$. floribunda a hirsuta sin tricomas glandulares en $A$. grandifolia, A. mexicana y A. occidentalis.

El tamaño del fruto varía de 3 a $6 \mathrm{~mm}$ de largo en las especies estudiadas, los más grandes se presentan en $A$. occidentalis y los más pequeños en $A$. coriacea. $\mathrm{Su}$ rostro mide de 0.2 a $3.3 \mathrm{~mm}$ de largo. La proporción del tamaño del fruto con respecto al rostro es mayor en $A$. coriacea y menor en $A$. occidentalis.

La semilla de las especies mexicanas es obovada a ampliamente obovada (2:16:5) y comprimida, a diferencia de las asiáticas en las cuales la forma es lanceolada y más bien cilíndrica. El tamaño varía de 1.4 a $2.5 \mathrm{~mm}$ de largo y 1.2 a $2.0 \mathrm{~mm}$ de ancho. La superficie vista al MEB es finamente coliculada (Fig. 11). Las celdas en la superficie son de 30-50 $\mu \mathrm{m}$ en A. floribunda y A. occidentalis, y de 20-35 $\mu \mathrm{m}$ en $A$. grandifolia y $A$. mexicana. Los cotiledones contienen abundante endospermo, el eje embrionario es pequeño, recto y situado en la porción superior.

Cromosomas: El número cromosómico básico para la familia Caprifoliaceae parece ser nueve, ya que es el encontrado para la mayoría de los géneros (Chatterjee, 1968; Sax y Kribs, 1930), en otros casos se observa variación de 2n=32, 36 . 

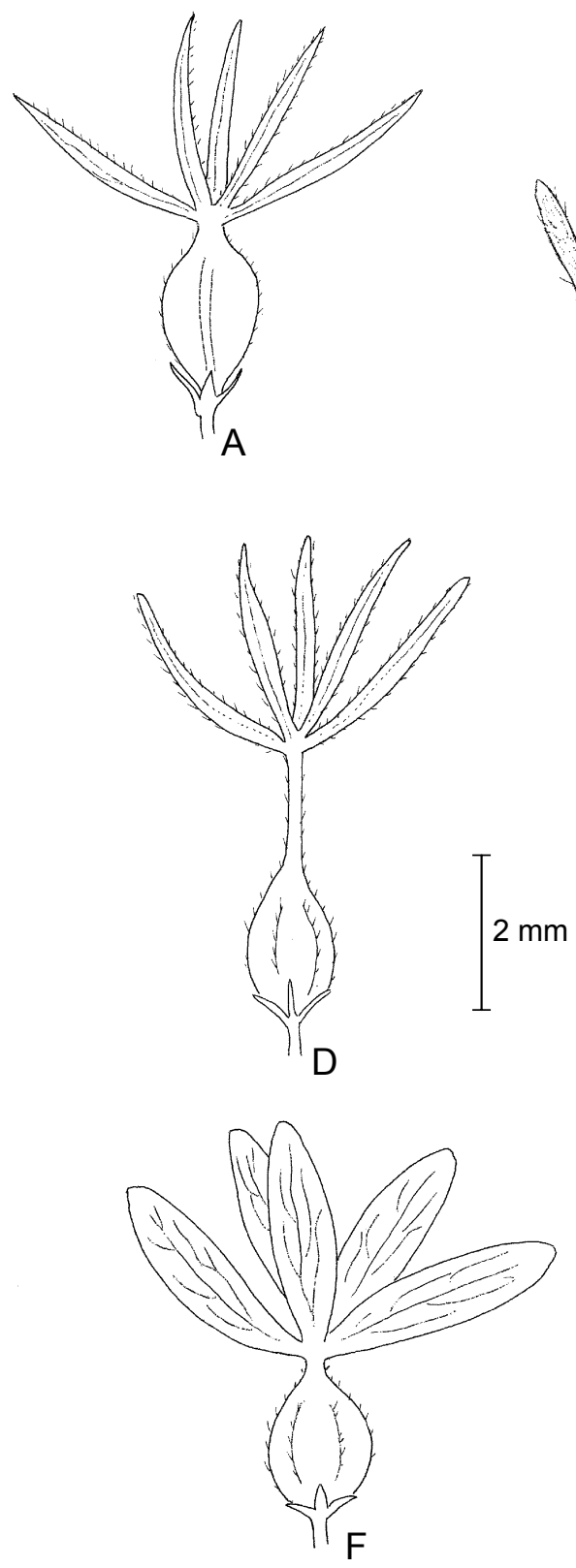
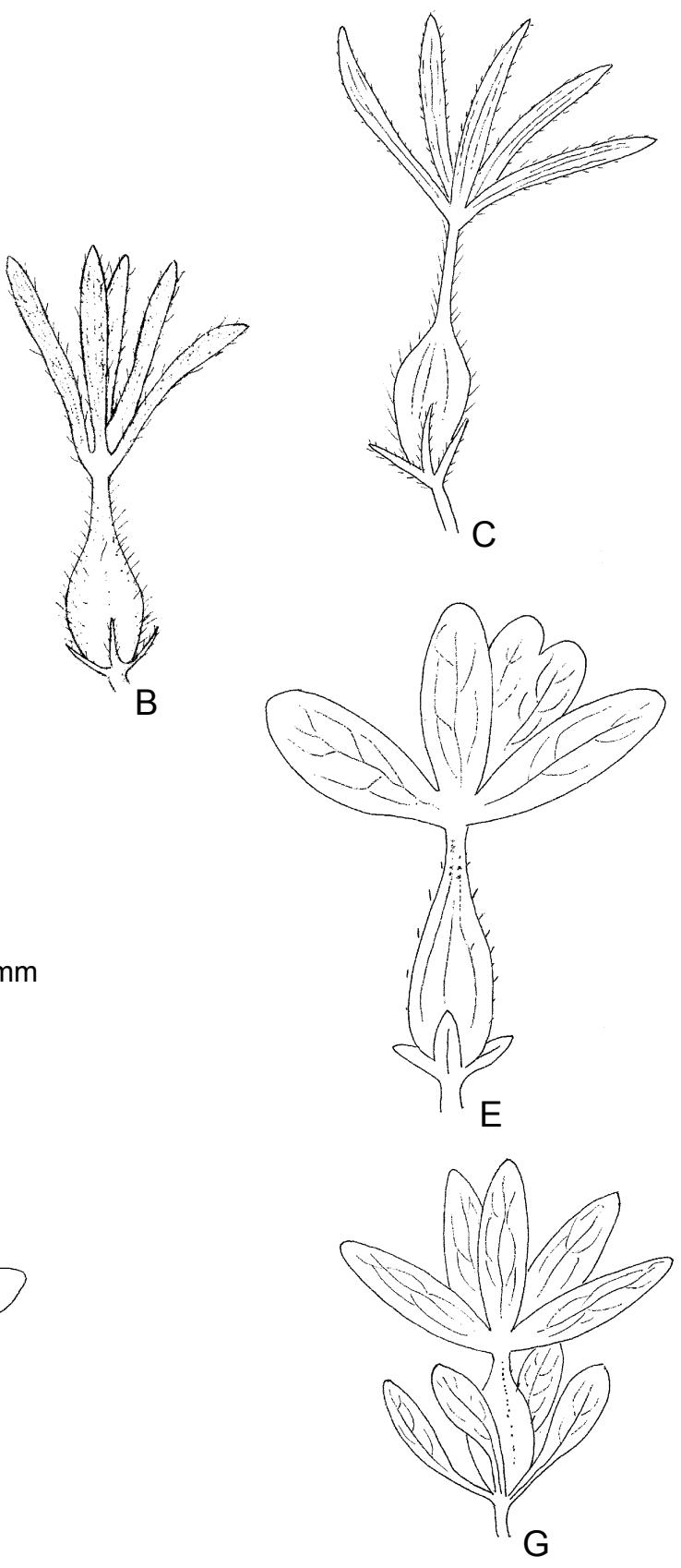

Fig. 10. Fruto con calículo en Abelia. A. A. coriacea; B. A. mexicana; C. A. grandifolia; D. A. occidentalis; E. A. × grandiflora; F. A. floribunda var. floribunda y G. A. floribunda var. foliacea. Nótese la forma y tamaño de las bracteolas del calículo en las diferentes especies. 

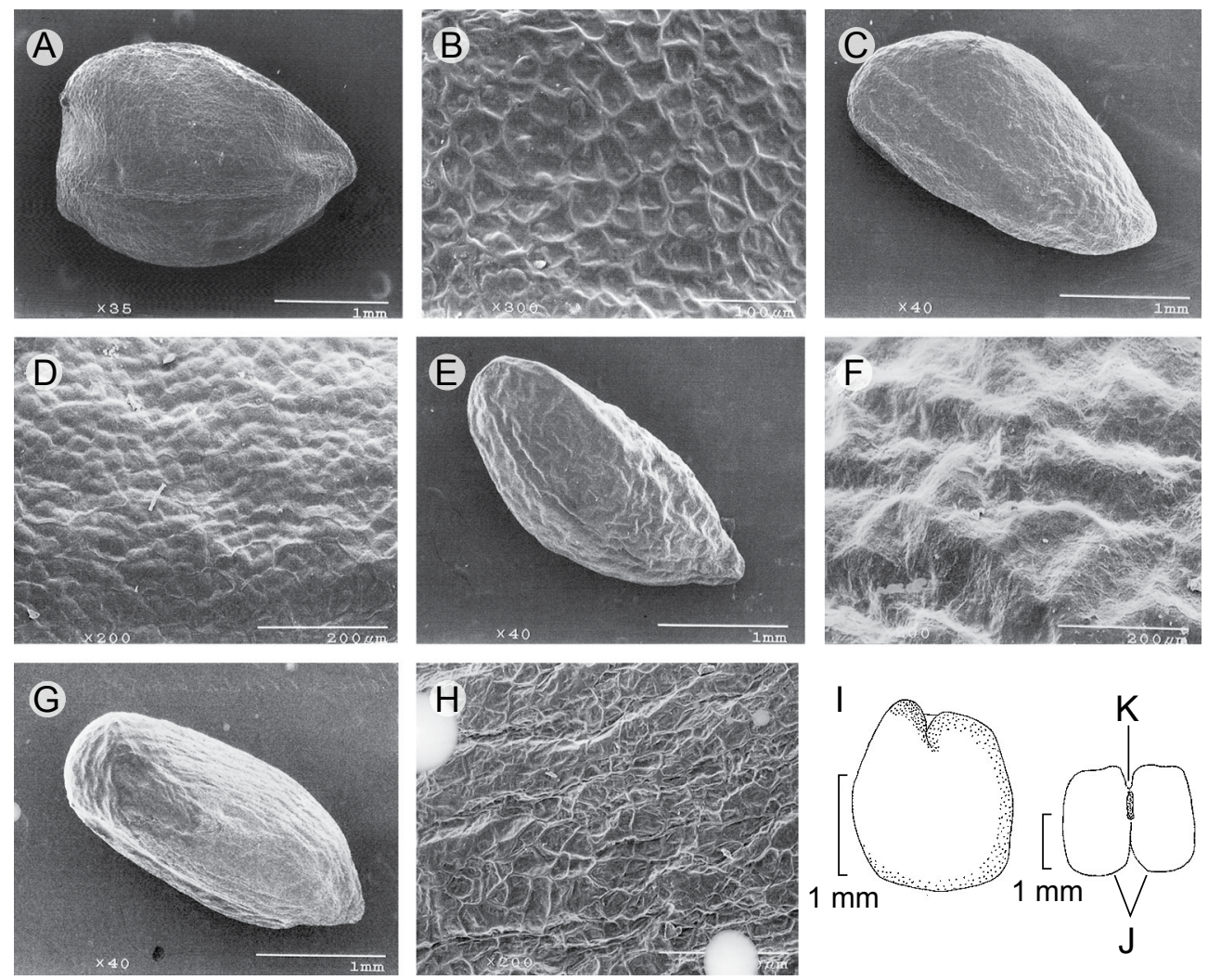

Fig. 11. Semilla en Abelia. Semillas vistas al microscopio electrónico de barrido. A y B. semilla y su superficie en $A$. floribunda; C y D. en A. grandifolia; E y F. en A. mexicana; G y H. semilla y su superficie en $A$. occidentalis. Dibujo de semilla en A. floribunda. I. vista lateral, J. cotiledones, K. embrión.

Sax y Kribs (1930) mencionan que algunas de las especies de Abelia y Kolkwitzia que no concuerdan con el número cromosómico básico, por poseer 16 cromosomas gaméticos, pueden ser interpretados como tetraploides que han perdido dos pares de cromosomas.

En las células de polen en desarrollo de $A$. occidentalis se observaron 16 cromosomas en la telofase I, mientras que las células en división en los extremos de raicillas mostraron en todos los casos $2 n=32$ (Fig. 12). Los cromosomas son muy pequeños y cortos, como los reportados por Sax y Kribs (1930) en A. schumannii. Puesto que el número cromosómico básico de la familia Caprifoliaceae es $x=(8) 9$, las especies de Abelia con $2 n=32$ pueden ser consideradas como tetraploides. 


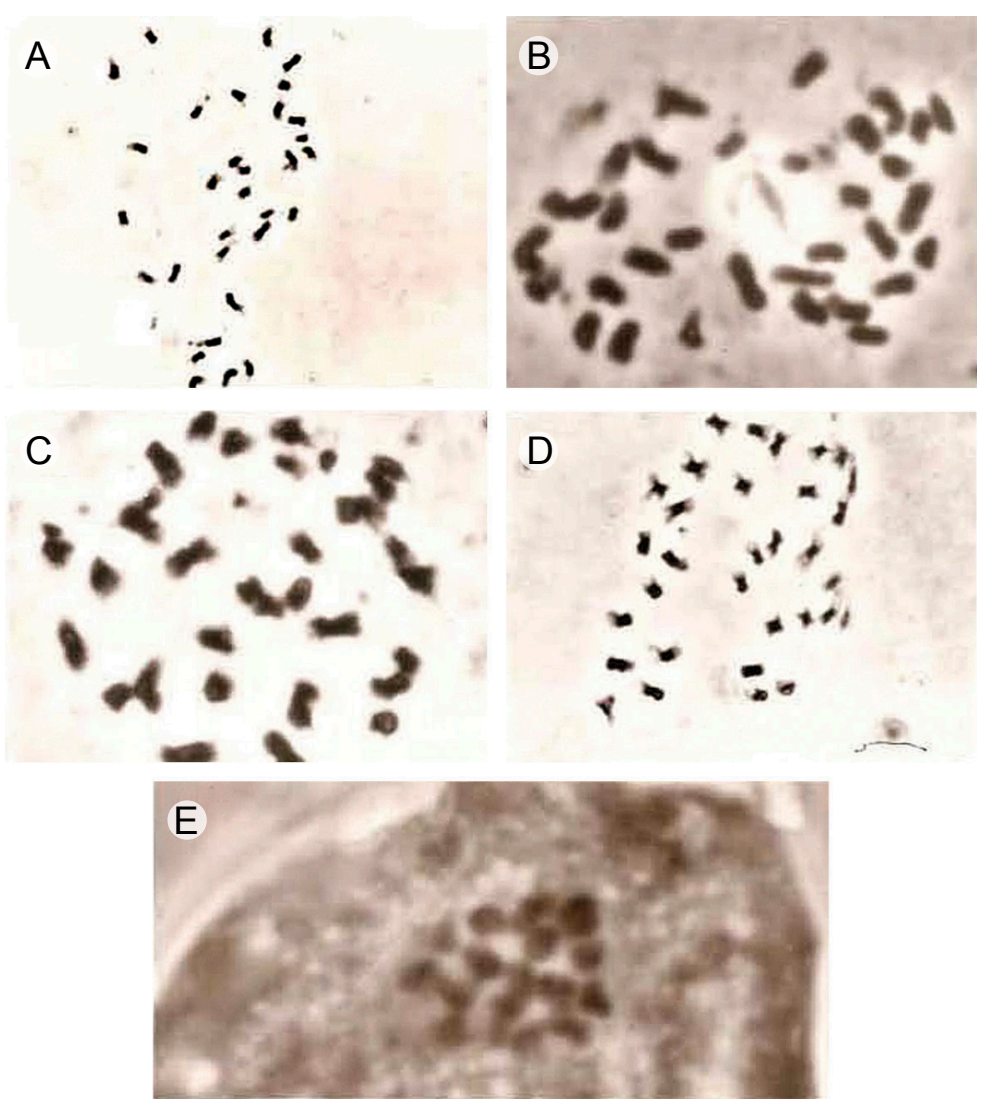

Fig. 12 . Células radicales donde se muestran los cromosomas en A. floribunda $2 n=32$ (J.A. Villarreal 8602); B. A. grandifolia $2 n=32$ (E. Carranza 5388); C. A. mexicana $2 n=32(J$. A. Villarreal 8601); D y E. A. occidentalis, $2 n=32, \mathrm{n}=16$ (J. A. Villarreal 8180$)$.

\section{DISCUSIÓN}

El género Abelia ha sido tratado taxonómicamente con base en los caracteres florales y de manera secundaria, en los vegetativos (Bailey, 1977; Hara, 1983 y Landrein et al., 2012). Es sobresaliente la forma, color y tamaño de la corola, la disposición de las flores y la vestidura, así como la forma y tamaño de la hoja. Las especies con amplia distribución muestran variación morfológica en sus poblaciones. Así, aquellas que habitan lugares áridos frecuentemente tienen hojas y flores más pequeñas, mientras que las que provienen de habitats mésicos son más grandes. 


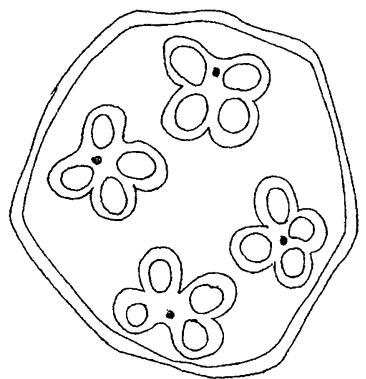

$\mathrm{E}$
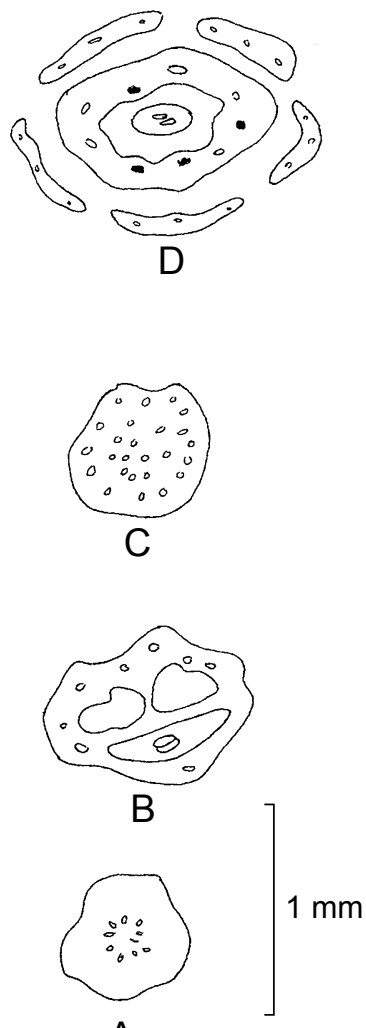

A

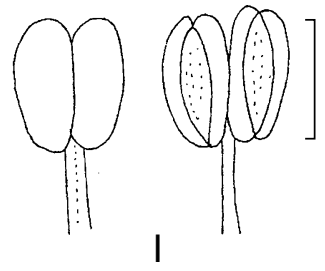

$2 \mathrm{~mm}$
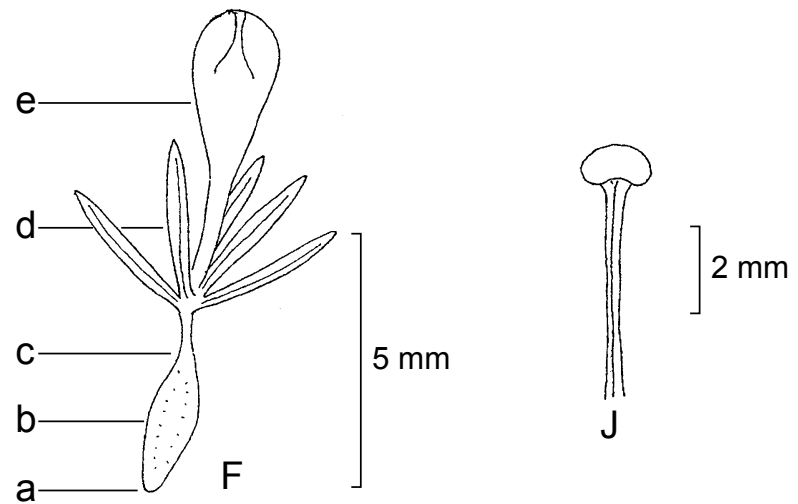

$5 \mathrm{~mm}$

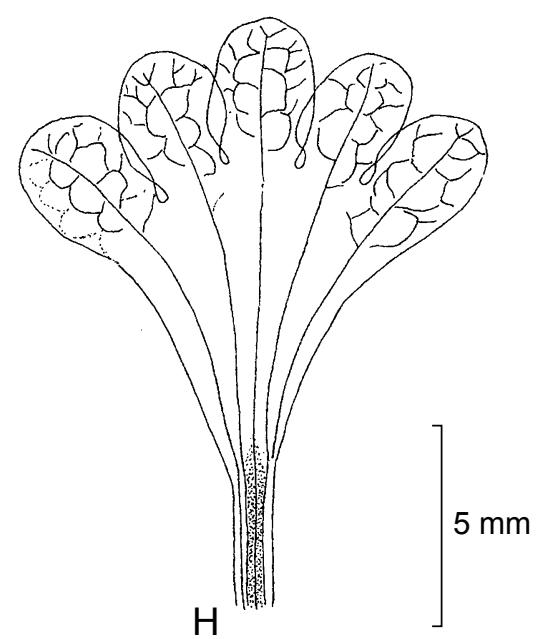

Fig. 13. Vascularización de flores de Abelia coriacea. A-E: diagramas de cómo es vista en una serie de cortes al nivel indicado en la figura F; las trazas de los estambres están señalados en círculos negros en D-E; diagramas que muestran la vascularización en material aclarado de lóbulos del cáliz en $\mathrm{G}$, y la corola en $\mathrm{H}$, la parte sombreada en el tubo de la corola corresponde al nectario. I. estambres en su cara adaxial (izquierdo) y abaxial (derecho). J. estilo y estigma. 

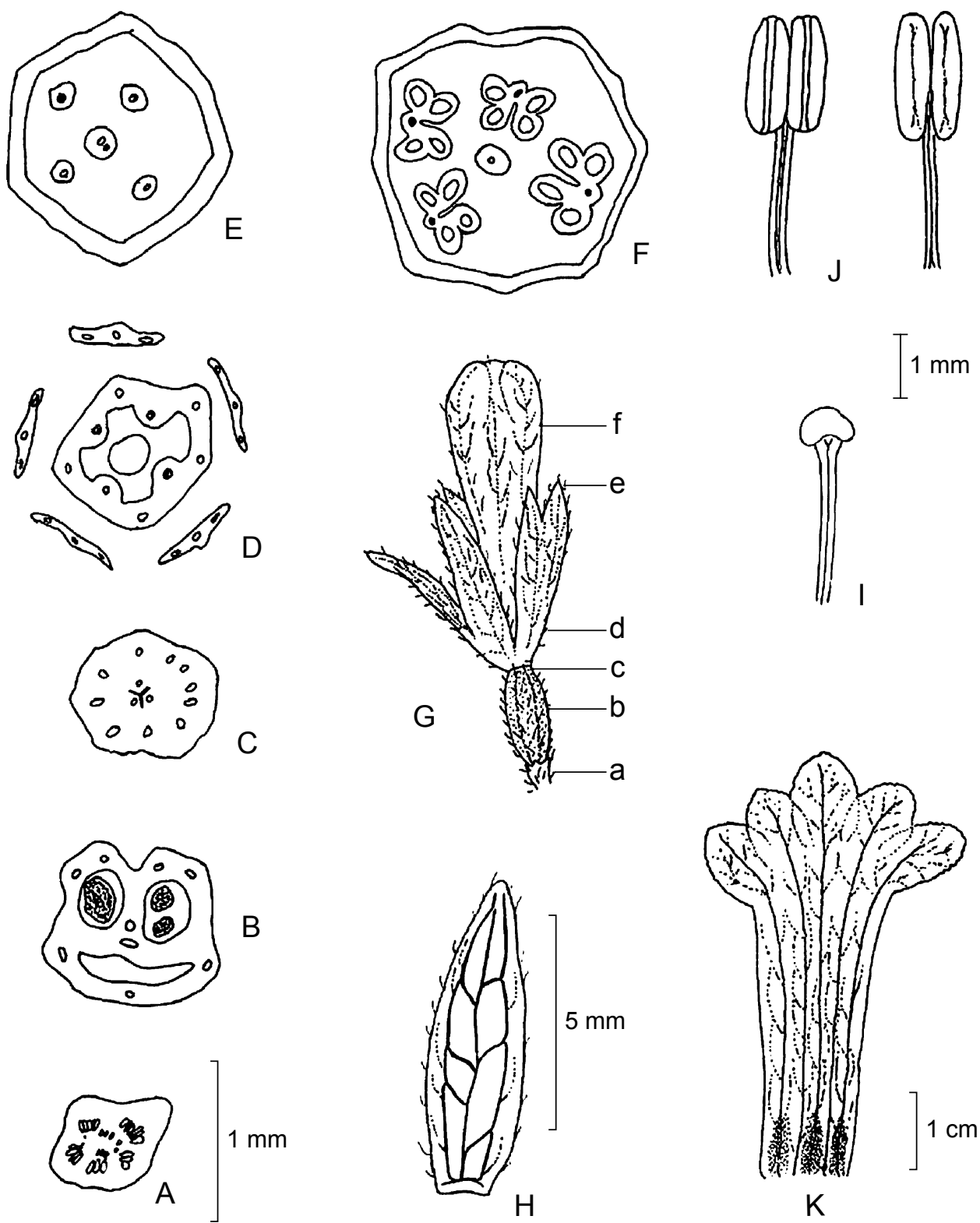

Fig. 14. Vascularización de flores de Abelia floribunda. A-F: diagramas de cómo es vista en una serie de cortes al nivel indicado en la figura G; las trazas de los estambres están señalados en círculos negros en D-F; diagramas que muestran el sistema vascular en material aclarado de lóbulos del cáliz en $\mathrm{H}$, y la corola en $\mathrm{K}$, la parte sombreada en el tubo de la corola corresponde al nectario. I. estilo y estigma. J. estambres en su cara adaxial (izquierdo) y abaxial (derecho). 

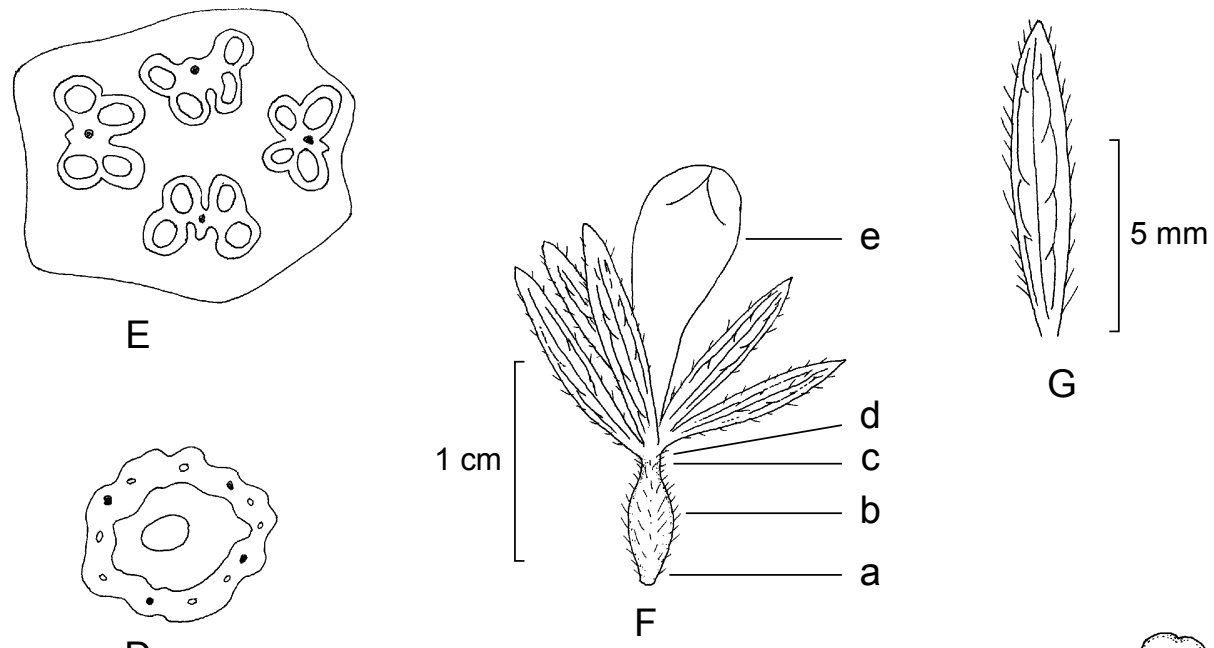

D
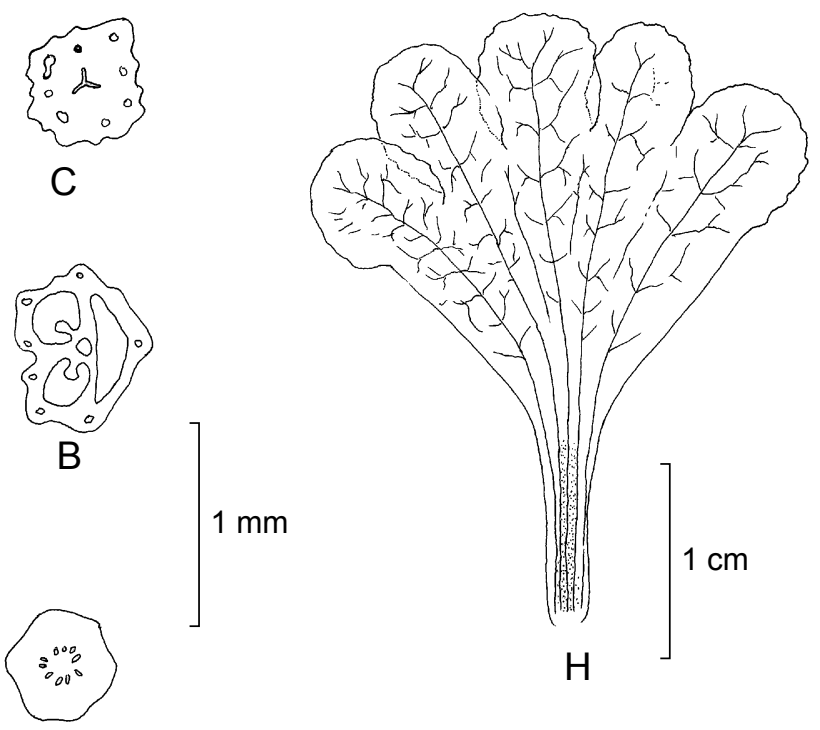

A

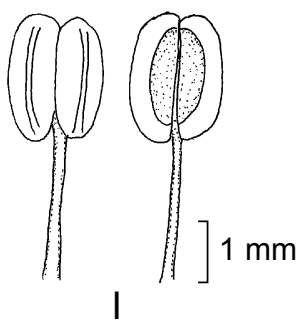

Fig. 15. Vascularización de flores de Abelia grandifolia. A-E: diagramas de cómo es vista en una serie de cortes al nivel indicado en la figura F; las trazas de los estambres están señalados en círculos negros en D-E; diagramas que muestran el sistema vascular en material aclarado de lóbulos del cáliz en $\mathrm{G}$, y la corola en $\mathrm{H}$, la parte sombreada en el tubo de la corola corresponde al nectario. I. estambres en su cara adaxial (izquierdo) y abaxial (derecho). J. estilo y estigma. 

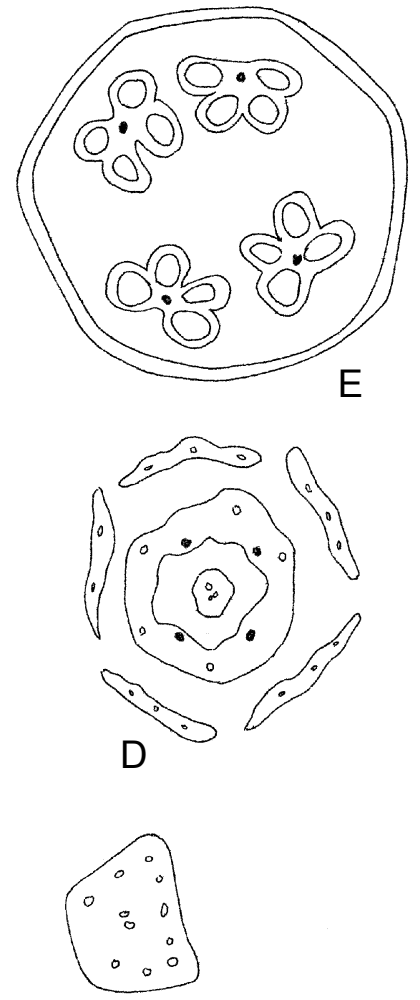

C
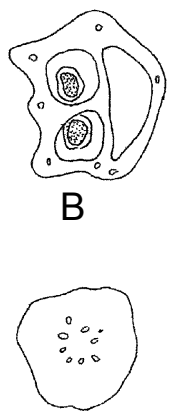

A

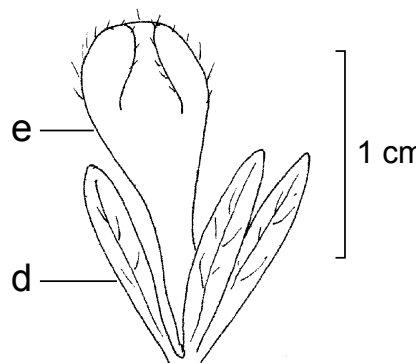

$\mathrm{F}$
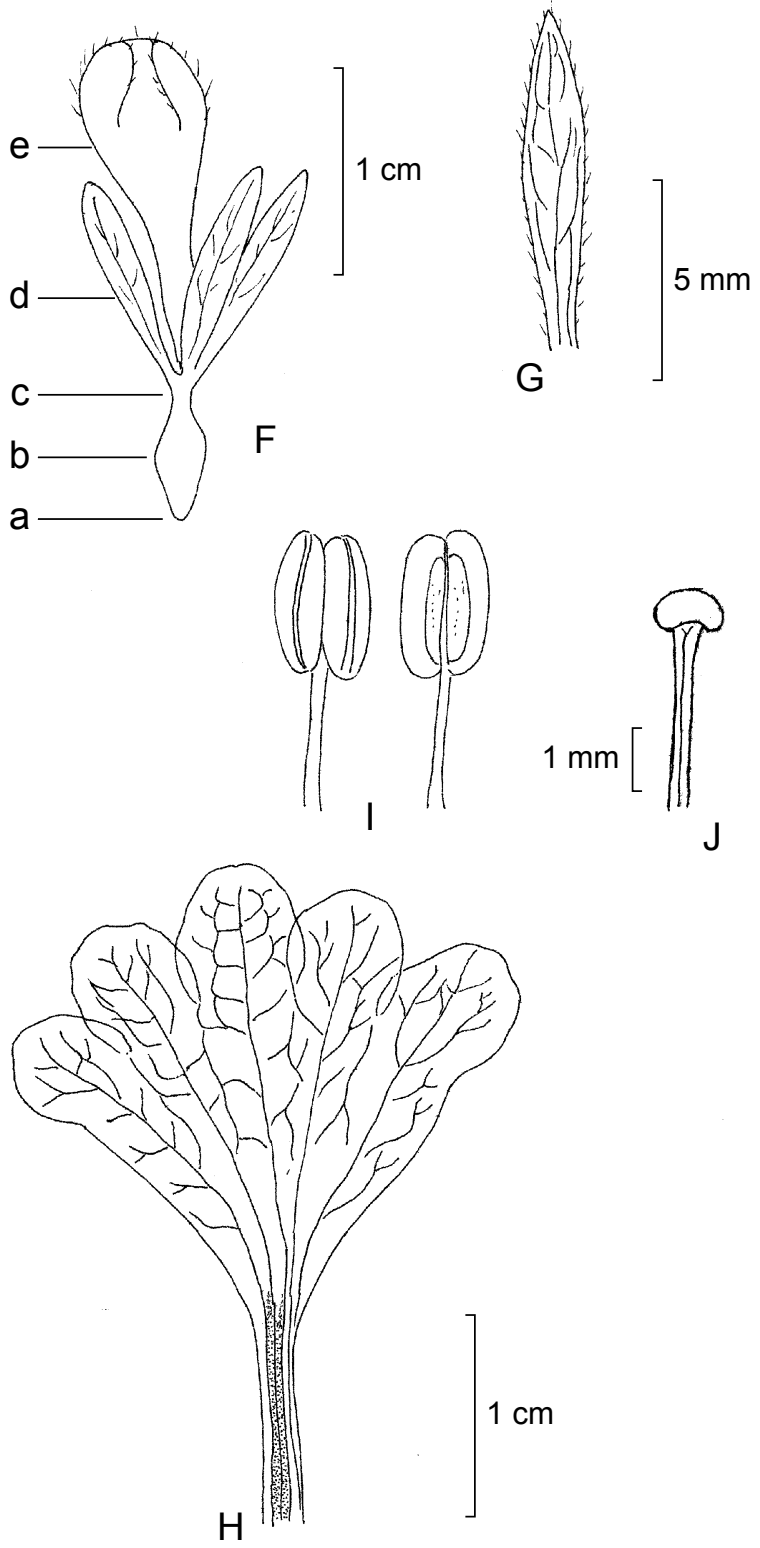

Fig. 16. Vascularización de flores de Abelia mexicana. A-E: diagramas de cómo es vista en una serie de cortes a nivel indicado en la figura F; las trazas de los estambres están señalados en círculos negros en D-E; diagramas que muestran el sistema vascular en material aclarado de lóbulos del cáliz en G, y la corola en $\mathrm{H}$, la parte sombreada en el tubo de la corola corresponde al nectario. I. estambres en su cara adaxial (izquierdo) y abaxial (derecho). J. estilo y estigma. 

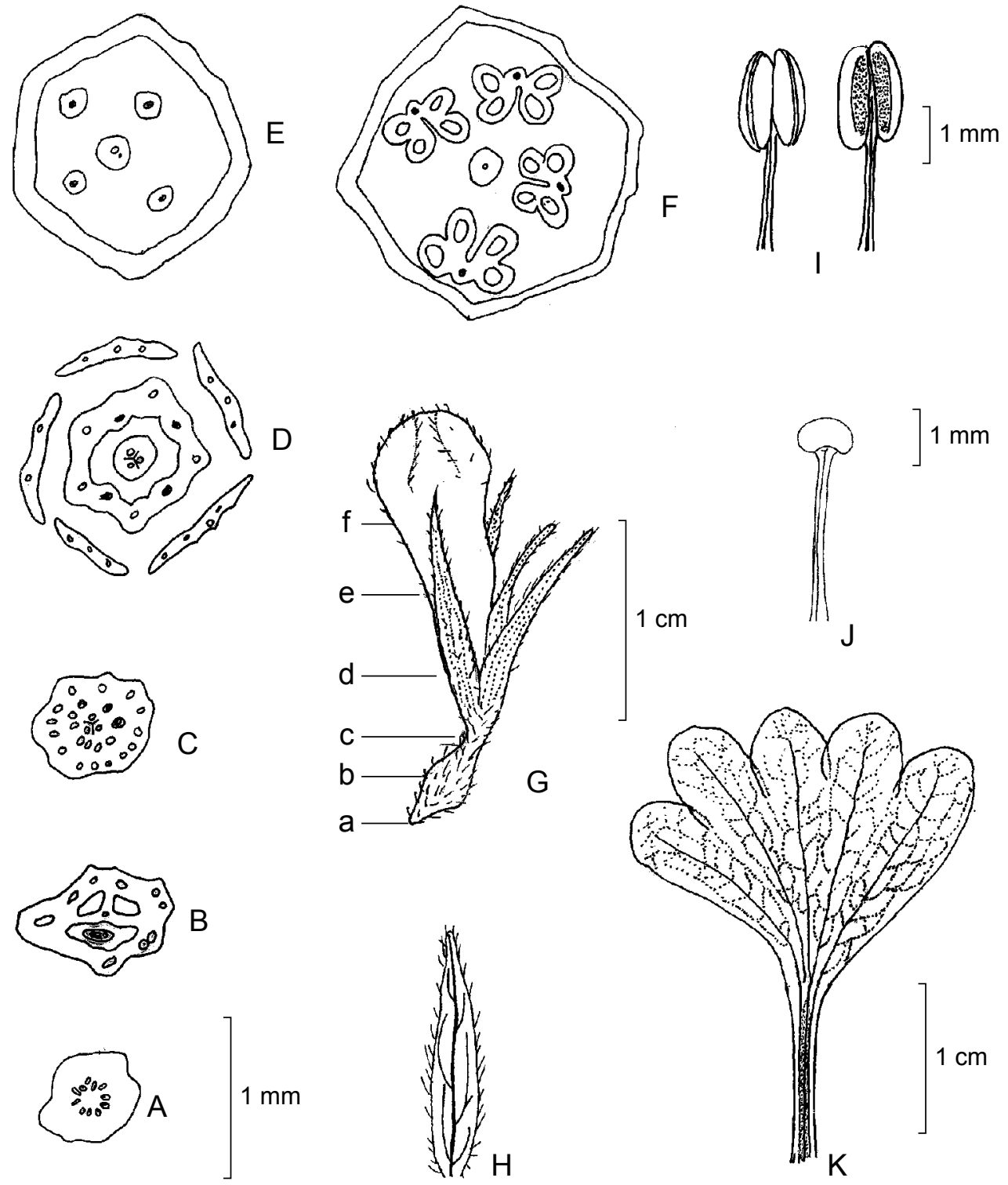

Fig. 17. Vascularización de flores de Abelia occidentalis. A-F: diagramas de cómo es visto en una serie de cortes al nivel indicado en la figura G; las trazas de los estambres están señalados en círculos negros en D-F; diagramas que muestran el sistema vascular en material aclarado de lóbulos del cáliz en $\mathrm{H}$, y la corola en $\mathrm{K}$, la parte sombreada en el tubo de la corola corresponde al nectario. I. estambres en su cara adaxial (izquierdo) y abaxial (derecho). J. estilo y estigma. 
Caracteres como el tamaño, forma y textura de la hoja ayudan a la diferenciación de los taxa a nivel de especie y de variedad. Las especies americanas se caracterizan por tener en su mayoría hojas con base y ápice redondeado a obtuso, raramente agudos. Estos últimos son más frecuentes en las especies asiáticas (Hara, 1983). En el presente trabajo, la anatomía foliar reveló que algunos caracteres, como el grosor de la hoja y el número de hileras de células en empalizada, pueden ser empleados para la diferenciación de las especies estudiadas. Se ha encontrado que el desarrollo del tejido en empalizada en la hoja está relacionado con la exposición directa a la luz (Esau, 1977).

Esau (1977) indica que las hojas de las plantas mesofíticas son delgadas, con el parénquima en empalizada localizado en la parte superior de la hoja y el esponjoso en la parte inferior (bifacial) en igual proporción. En contraste, en las plantas xerofíticas las hojas son pequeñas y compactas, con mesófilo grueso y con más tejido de empalizada que esponjoso. La revisión de la anatomía de la hoja de Abelia reveló que ambos tipos de mesófilo se presentan en las especies americanas, con relación directa al ambiente en que se encuentran. Abelia coriacea y $A$. grandifolia de regiones más áridas tienen hojas con parénquima más desarrollado; por otro lado, A. floribunda, A. mexicana y A. occidentalis de condiciones de mayor humedad, lo presentan menos engrosado. Algunos caracteres tales como la venación de la hoja y los sépalos, así como el tipo de estomas se mantienen constantes en todas las especies.

El arreglo floral de las especies estudiadas es de cimas con (1-)2(-3) flores, al parecer derivadas de un tirso. Landrein y Prenner (2013), estudiando la morfología y la ontogenia de la inflorescencia en caprifoliáceas, concluyen que un tirso compuesto es el patrón básico en el grupo, ubicando a Vesalea en un conjunto intermedio dentro de las tendencias evolutivas de la inflorescencia. Abelia floribunda usualmente presenta 1(-2) flores por cima. Es la única especie mexicana estudiada por los autores, quienes interpretan la pérdida de flores como una condición propia de ésta y otras abelias asiáticas. El análisis de más elementos morfológicos de la sección Vesalea ayudará a entender mejor su filogenia.

El estudio del polen en Caprifoliaceae ha revelado considerable variación morfológica tanto a nivel de microscopio óptico (Arreguín, 1980) como electrónico (Donoghue, 1985). Los patrones de variación en general están relacionados con la taxonomía del grupo y la segregación en tribus. Donoghue (1985) encuentra que el polen en Viburnum presenta pequeñas variaciones que pueden ser consideradas de utilidad taxonómica. Remarca que los cambios en la morfología polínica deben ser lo suficientemente contrastantes para eliminar la variación debida a las condiciones 
ambientales, las que aparecen durante el desarrollo de la planta y las determinadas por el método de preparación. Para Abelia, el tamaño promedio del polen, el grosor de la exina, los colpos y las espinas para las especies revisadas no muestran diferencias contrastantes entre los taxa americanos. El número de perforaciones del tectum solo se tomó de las muestras fotografiadas, por lo que se requiere de más observaciones que corroboren la información dada anteriormente. Sin embargo, las pequeñas variaciones en el tamaño de las espinas y la cantidad de perforaciones, indican muy escasa distinción entre especies. Un estudio más detallado ayudaría a aclarar las divergencias. Arreguín (1980) describe el polen de A. floribunda como tetraporado, con una exina delgada y espinas pequeñas, lo cual difiere de lo encontrado en el presente trabajo. En todos los miembros de Caprifoliaceae éste es normalmente de tres aperturas, con granos que ocasionalmente muestran cuatro (Bassett y Crompton, 1970). La condición de granos tri y tetra-colpados se observó en las especies estudiadas y concuerda con lo reportado por Donoghue (1985) para A. spathulata. En general se encontró un alto grado de similitud con lo descrito para las especies asiáticas (sección Abelia), de acuerdo con lo estudiado por Erdtman (1943) y Donoghue (1985) y lo observado en este trabajo en $A$. $\times$ grandiflora, $A$. sanguinea y $A$. serrata. Sin embargo, es importante remarcar que las características de la morfología del polen en las especies asiáticas fueron tomadas en cuenta por Rehder (1977) para proponer la separación de la sección Zabelia. Su polen se caracteriza por ser tricolpado, liso, zonorado y con una banda ecuatorial continua (Erdtman, 1943; Fukuoka, 1968; Hara, 1983). En resumen, la palinología ha servido para delimitar grupos en Abelia.

El estudio de la filogenia basado en las características del polen coloca a Abelia en la tribu Linnaeeae, la cual muestra relaciones con Valerianaceae y Dipsacaceae (Jacobs et al., 2010), que actualmente son reconocidas como subfamilias Valerianoideae y Dipsacoideae en Capifroliaceae s. 1. (Stevens, 2001 onwards). Los granos con un tipo de exina con tectum sostenido por columelas y espinas supratectadas parece corresponder a una condición ancestral presente en Abelia y de la cual posiblemente derivó el polen semitectado e intectado como el de Viburnum (Donoghue, 1985).

El tipo de glándula nectarífera y su localización diferencia al conjunto asiático, ubicado por Fukuoka (1968) en la sección Abelia. Las propias de las especies americanas son en forma de banda, condición que también es reportada para Lonicera japonica por Fahn (1978). Este tipo es considerado por Wagenitz y Laing (1984) como una condición avanzada. El número de bandas glandulares varía de tres en A. floribunda a una en A. coriacea, A. grandifolia, A. mexicana y A. occidentalis. 
Los nectarios dispuestos en cintas constituyen una característica diferencial de las abelias americanas (sección Vesalea).

La anatomía floral de las especies americanas no difiere de lo descrito por Wilkinson (1948) para el género. El ovario en Abelia, como en otros géneros de Linnaeeae, muestra una reducción en el número de carpelos y la fusión de haces vasculares (Wilkinson, 1949). En este trabajo observamos esta unión de elementos vasculares que bordean el lóculo fértil. Aunque se ha aseverado que en el ovario un lóculo es fértil y los otros dos estériles (Wilkinson, 1948), encontramos que ocasionalmente en A. floribunda y A. mexicana los frutos desarrollan semillas en una de las otras dos cavidades. Si bien la fructificación es abundante, muchos de los frutos no desarrollan semilla. Ésta es ancha en los taxa americanos y estrecha en los asiáticos (Hara, 1983). Tal carácter, aunado a la forma más bien cilíndrica del ovario y fruto, sumado a la presencia de una glándula en una prominencia de la base de la corola, diferencian a los elementos del Viejo Mundo de los del Nuevo.

La familia Caprifoliaceae, de acuerdo con Takhtajan (1980), es más bien un grupo heterogéneo, lo cual es congruente con los resultados de recientes estudios morfológicos (Landrein et al., 2012) y filogenéticos (APG III, 2009). Se observan diferencias en el polen (Donoghue, 1985), nectarios (Wagenitz y Laing, 1984) y estructura cromosómica (Sax y Kribs, 1930), lo cual refuerza la idea de que existen líneas evolutivas diferentes en la misma (Takhtajan, 1980; Dahlgren, 1980; Landrein y Prenner, 2013). Este punto de vista también es consistente con los resultados encontrados por Hsu (1983) en un análisis fenético utilizando datos morfológicos para la familia, con el análisis de productos químicos secundarios (Bohm y Glennie, 1971), con evidencias inmunológicas (Hillebrand y Fairbrothers, 1970) y con estudios del gen $r b c \mathrm{~L}$ del cloroplasto para Viburnum (Donoghue et al., 1992; Downie y Palmer, 1992).

Abelia (s. 1.) tampoco se muestra como un conjunto homogéneo y monofilético (Landrein, 2010). La separación de Abelia en las secciones Abelia y Vesalea, con base en evidencias morfológicas fue propuesta en las clasificaciones de Fukuoka (1968) y Hara (1983). A pesar de que en estudios de filogenia basados en morfología (Villarreal-Quintanilla et al., 2013), en biología molecular (Jacobs et al., 2010) y de morfología de la inflorescencia (Landrein et al., 2012), el conjunto Vesalea se interpreta como monofilético, éste se presenta siempre fuertemente relacionado con un grupo de la sección Abelia. Es por eso que consideramos que la segregación del género Vesalea, apoyándose en el tipo de glándula nectarífera y forma del ovario, nos parece una propuesta débil que debe reforzarse con más evidencias. 


\section{AGRADECIMIENTOS}

Agradecemos a la T. L. Q. Angélica Martínez su apoyo en el trabajo de anatomía, a la Dra. Sara Fuentes por la toma de fotografías en el microscopio electrónico, al Dr. Armando Rodríguez por su apoyo en la toma de fotografías y conteos cromosómicos. Al personal de los Laboratorios de Semillas y Citogenética de la Universidad Autónoma Agraria Antonio Narro por las facilidades para realizar la germinación de semillas y conteos cromosómicos. A J. Arturo de Nova por permitir el uso de la foto de la flor de Abelia coriacea y a Sven Landrein las de A. floribunda, A. grandifolia y A. occidentalis en la figura 5.

\section{LITERATURA CITADA}

APG III. 2009. An update of the Angiosperm Phylogeny Group classification for orders and families of flowering plants: APG III. Bot. J. Linn. Soc. 161(2): 105-121.

Arreguín, M. L. 1980. Morfología de los granos de polen de la familia Caprifoliaceae en México. Memorias del III Coloquio sobre Paleobotánica y Palinología. Colección Científica, No. 86. Instituto Nacional de Antropología e Historia. México, D.F., México. pp. 29-51.

Backlund, A. y N. Pyck. 1998. Diervillaceae and Linnaeaceae, two new families of caprifolioids. Taxon 47(3): 657-661.

Bailey, L. H. 1977. Manual of cultivated plants. McMillan Publ. Co. Inc. New York, USA. $1116 \mathrm{pp}$.

Bassett, I. J. y C. W. Crompton. 1970. Pollen morphology of the family Caprifoliaceae in Canada. Pollen et Spores 12: 365-380.

Bohm, B. A. y C. W. Glennie. 1971. A chemosystematic study of the Caprifoliaceae. Canad. J. Bot. 49: 1799-1807.

Chatterjee, T. 1968. Study of the structure and behavior of chromosomes of different taxa of Caprifoliaceae. J. Cytol. Genet. 3: 60-65.

Dahlgren, R. 1980. A revised system of classification of the angiosperms. Bot. J. Sci. 80: 91-124.

Donoghue, M. J. 1985. Pollen diversity and exine evolution in Viburnum and the Caprifoliacae sensu lato. J. Arnold Arbor. 66: 421-469.

Donoghue, M. J., R. G. Olmstead, J. F. Smith y J. D. Palmer. 1992. Phylogenetic relationships of Dipsacales based on $r b c \mathrm{~L}$ sequences. Ann. Missouri Bot. Gard. 79: 333-345.

Downie, S. R. y J. D. Palmer. 1992. Restriction mapping of the chloroplast DNA invert repeat: A molecular phylogeny of the Asteridae. Ann. Missouri Bot. Gard. 79: 266-283.

Erdtman, G. 1943. An introduction to pollen analysis. Chronical Botanica Company. Waltham, USA. 1322 pp. 
Esau, K. 1977. Anatomy of seed plants. 2a ed. John Wiley \& Sons. New York, USA. 550 pp. Fahn, A. 1978. Anatomía vegetal. H. Blume Ediciones. Madrid, España. pp. 524-531.

Fukuoka, N. 1968. Phylogeny of the tribe Linnaeeae. Acta Phytotax. Geobot. 23(3): 82-94.

Good, R. 1974. The geography of the flowering plants. 4a. ed. Longman, Inc. London, UK. 574 pp.

Hara, H. 1983. A revision of Caprifoliaceae of Japan with reference to allied plants in other districts and the Adoxaceae. Ginkgoana; contributions to the flora of Asia and the Pacific region. Vol. 5. Academic Sci. Books. Tokyo, Japan. 336 pp.

Hickey, L. F. 1973. Classification of the architecture of dicotyledonous leaves. Amer. J. Bot. 60(1): 17-33.

Hillebrand, G. R. y D. E. Fairbrothers. 1970. Phytoserological systematic survey of the Caprifoliaceae. Brittonia 22(2): 125-133.

Hsu, P. S. 1983. A preliminary numerical taxonomy of the family Caprifoliaceae. Acta Phytotax. Sinica 21(1): 26-33.

Jacobs, B., N. Pyck. y E. Smets. 2010. Phylogeny of the Linnaea clade: are Abelia and Zabelia closely related? Mol. Phylog. Evol. 57(2): 741-752.

Landrein, S. 2010. Diabelia a new genus of the tribe Linnaeeae, subtribe Linnaeinae (Caprifoliaceae). Phytotaxa 3: 34-38.

Landrein, S., G. Prenner, M. W. Chase y J. J. Clarkson. 2012. Abelia and relatives: Phylogenetics of Linnaeeae (Dipsacales-Caprifoliaceae s. 1.) and interpretation of their inflorescence morphology. Bot. J. Linn. Soc. 169: 692-713.

Landrein, S. y G. Prenner. 2013. Unequal twins? Inflorescence evolution in the twinflower tribe Linnaeeae (Caprifoliaceae s. 1.). Int. J. Plant Sci. 174(2): 200-233.

Metcalfe, C. R. y L. Chalk. 1950. Anatomy of the dicotyledons. Claredon Press. Oxford, UK. pp. 124-132.

Rehder, A. 1977. Manual of cultivated trees and shrubs. 2a. ed. Macmillan Publ. Co., Inc. New York, USA. pp. 846-847.

Roe, K. E. 1971. Terminology of hairs in the genus Solanum. Taxon 20(4): 501-508.

Sax, K. y D. A. Kribs. 1930. Chromosomes and phylogeny in Caprifoliaceae. J. Arnold Arbor. 11: 147-153.

Stevens, P. F. 2001 onwards. Angiosperm Phylogeny Website. Version 12, july 2012 [and more or less continously updated since]. http://www.mobot.org/MOBOT/research/ APweb/.

Takhtajan, A. L. 1980. Outline of a classification of flowering plants (Magnoliophyta). Bot. Rev. 46(3): 225-359.

Van Cotthem, W. R. 1970. A classification of stomatal types. Bot. J. Linn. Soc. 63(3): 235246.

Villarreal-Quintanilla, J. Á. 2000. Caprifoliaceae. Flora del Bajío y de Regiones Adyacentes 88: 1-17.

Villarreal-Quintanilla, J. Á. 2002. Caprifoliaceae. Flora de Veracruz 126: 1-16.

Villarreal-Quintanilla, J. Á. 2008. Caprifoliaceae. Flora del Valle de Tehuacán-Cuicatlán 58: $1-7$.

Villarreal-Quintanilla, J. Á., J. L. Villaseñor-R. y A. E. Estrada-C. 2013. Sistemática del género Abelia (Caprifoliaceae) en México. Acta Bot. Mex. 102: 99-128. 
Wagenitz, G. y B. Laing. 1984. Die Nektarien der Dipsacales und ihre systematiche bedeutung. Bot. Jahrb. Syst. 104: 91-113.

Wilkinson, A. M. 1948. Floral anatomy and morphology of some species of the tribes Linnaeeae and Sambuceae of the Caprifoliaceae. Amer. J. Bot. 35: 365-371.

Wilkinson, A. M. 1949. Floral anatomy and morphology of Triosetum and the Caprifoliaceae in general. Amer. J. Bot. 36: 481-489.

Recibido en enero 2011.

Reactivado en julio 2013.

Aceptado en diciembre de 2013. 
